\title{
Process, Order and Stability in Veblen ${ }^{1}$
}

\author{
Tony Lawson \\ Faculty of Economics, \\ Sidgwick Avenue, \\ Cambridge, CB3 9DD \\ Tony.Lawson@econ.cam.ac.uk \\ Aug 26, 2014
}

\begin{abstract}
In this essay I tease out the notion of social order that underpins Veblen's numerous contributions, and examine its development over time. In piecing together various components of Veblen's conception, in particular his notions of habit, institution and habituation, I challenge various existing interpretations of Veblen's thinking on these and related matters.
\end{abstract}

Keywords: Process, order, stability, history of thought, economic science, institution, habit, habituation, human nature, evolution, natural selection, Darwin, Spencer, Mendel.

JEL Codes: A1, A3, B1, B2, B3, B4, B5, Z1

\section{Introduction}

Few economists, I suspect, emphasise the processual nature of social reality as much as Veblen. He continually reminds us that the social realm, no less than the (non-social) natural realm, is a process of causal sequence, of cumulative causation. On this I think most historians of thought are in agreement. What, though, of a conception of social order and stability? Does Veblen provide the details of any, explicitly or otherwise? Although historians of thought are seemingly in further agreement that habit and institution constitute central categories in Veblen's thinking on these and related matters, thereafter division does set in. I suspect that, for good or ill, I am going to be adding to the latter. For, I am going to suggest that aspects at least of various prominent assessments of Veblen's account of some of these concerns, not least some of those widely accepted within the institutionalist tradition that most associates with Veblen, may not be quite right.

\section{Why bother?}

Why does any of this matter? First of all, ontological theorising per se always matters. All theories, methods, policies, etc., presuppose ontological conceptions whether they are rendered explicit and systematic or not. And very often, especially when left unexamined, they turn out not to be tenable as accounts of what they are about. An obvious example is the reliance upon methods of mathematical modelling in modern economics, which carry with them an implicit ontology of worlds of isolated atoms, easily shown to be inconsistent with the actual nature of social reality (see e.g., Lawson, 2003a, 2012b).

\footnotetext{
${ }^{1}$ Forthcoming Cambridge Journal of Economics. For helpful comments on an earlier draft I am grateful to participants at the first meeting of the International Working Party on the History of Ontological Thinking in Economics held in Nice in June 2013, to Bahar Araz and to three referees of the Cambridge Journal of Economics. For generous financial support for the research reported upon, I am also grateful to the Independent Social Research Foundation.
} 
If ontological preconceptions are always present and matter, then exercises in social understanding, including those in the history of thought, that ignore this insight are likely to be overly partial indeed.

But why specifically do categories like social order matter? In fact what even might social order mean? An order of any kind, I take it, is a form of arrangement; and any notion of a specifically social order presupposes the existence of various different human-interaction dependent features (practices, structures, processes, or whatever) that are organised/arranged in some fashion. Here I will take it that a social order means roughly a configuration of features such as these that may be regarded as possessing an internal coherence, a configuration wherein the various components are mutually accommodating and, most especially, facilitative of capable knowledgeable human interaction.

Although questions concerning the stability of any order may appear to be conceptually distinct to those concerning its nature, it is prima facie likely that any meaningful conception of a social order, so understood, will have notions of stability, and mechanisms of stability reinforcement, built in.

Clearly forms of social order, so interpreted, do obtain. Even so, questions about how they are possible, have come about, and have been, and continue to be, sustained are not trivial matters. Amongst other things, the operation of the second law of thermodynamics suggests that in all domains of the universe there are permanent tendencies to messiness or disorder, to an increase in entropy. So any emergence of apparent order in any domain and situation is a phenomenon warranting explanation, the social realm certainly no less than others.

Social order then is clearly an interesting topic of analysis for social theory in general, including the history of thought, the focus of the current paper. The chances are, indeed, that when a contributor has been influential, providing analyses that continue to resonate over a long period, his or her preconceptions at the level of ontology in general, and concerning issues of social order and cognate notions in particular, are likely to be significant, whether explicitly systematised or not. As such they are likely worth investigating at length.

Veblen is one such contributor who has been influential, and provides analyses that have continued over a long period to resonate. In fact he is especially important and interesting to consider on the issues before us. For, as already noted he does explicitly and regularly acknowledges the processual nature of social reality, and, as it happens, is repeatedly critical of those who fail to do so, or who fail to take this feature seriously. So, one might hope, and indeed expect, to find a definite account of order and of associated sources of stability within, and/or informing, his writings. Identifying any such Veblenian fundamentals is the challenge accepted in the current paper.

\section{Methodology}

Before commencing on the analysis proper I want to say something about my own methodological approach in this paper. Like everything else, history of thought can be done in different ways, some of which carry greater justification than others, relative to context. One very common, but highly questionable way of doing it, when the focus is a single author, is merely to take snippets, or small extracts, of an author's thought, removed from context, 
extracts that may have been written dozens of years apart, and to string them together to provide a preferred interpretation.

There are two hazards with this strategy, of course. First, the meaning of any term, or expression, depends on context, and can be easily misinterpreted if removed from its context. Second, authors, like everyone else, are liable to change their views over time. The form of consistency which most of us seek, or anyway can best hope to achieve, is of a more developmental or dialectical sort, much like the first notes and drafts for a thesis being rethought and transformed as the passing of time brings new arguments, experiences, resolutions of recognised contradictions, and reflection, etc..

Let me refer to any notion that small extracts of an author can always be understood in isolation as the fallacy of context-independent meaning, and to any supposition that an author's intentions can always be usefully unearthed by arbitrarily stringing together extracts from different sources possibly appearing years apart as the fallacy of presumed fixity of meaning.

Of course, albeit trivially, if the purpose is just to demonstrate that an author has at some point made a specific claim, or used specific categories, or referenced various literatures, or whatever, then selected extracts will be informative. The need to avoid both the noted fallacies applies only (or most obviously) when, as here, the goal is to determine an overall position of an author, at least on a certain set of issues.

It may turn out of course that on certain aspects at least an author does actually maintain the same or a similar view over a lengthy period. This clearly can be usefully indicated, though it remains something that requires demonstration. The latter, though, is quite a different exercise to conjoining various separate isolated snippets each appearing only at different periods, and claiming, without further argument, that the picture so constructed is a viewpoint necessarily held throughout (or even at all); it is the latter presumption which manifests the fallacy of presumed fixity of meaning.

How, then, might one seek to avoid the noted fallacies? Of course, it is impossible to consider any context in its entirety, or completely to avoid interpreting an author according to information relating to different stages of development. But still we can at least attempt to avoid the worst excesses of the errors involved. Two principles that warrant consideration in this regard, to state things more positively or constructively, might simply be framed as those of providing context and of being open to detecting dialectical development.

No doubt there are many viable ways of proceeding, even accepting these principles, each dependent on context. My strategy here will be as follows, given the situation represented by the totality of Veblen's output. Although his contributions all have relevance, I will first seek coherence in a later essay that is seemingly produced at the height if his intellectual thinking especially with regard to philosophical issues; if there is a relatively coherent convergent stance that warrants being associated with Veblen, it will presumably be found in such a source. Of course, it is sometimes the case that a given text, even if it contains the most mature account of an author, contains significant and seemingly irresolvable ambiguity, or is found to be overly partial, regarding various aspects of the concerns of the investigation. Only if/where such is found or appears to be the case will I turn to other contemporary (or if relevant, less contemporary) texts to see if clarification can thereby be achieved (though how this might happen depends on issue and context). 
Once I have set out the interpretation of Veblen's position that I find the most coherent in the contribution on which I focus, I turn to examine Veblen's earlier work to see if significant changes over time can be discerned ${ }^{2}$. I finally examine the broader range of Veblen's total contributions albeit in a less detailed fashion in order to assess whether tendencies already discerned appear to receive further generalised support or are perhaps notably contradicted.

The text I have in mind for the initial and primary analysis as an expression of Veblen's more mature thinking is Veblen's 1909 The Limitations of Marginal Utility. The latter is effectively a philosophical essay in which the categories that concern us, not least those of institution and habit, do figure explicitly and prominently. It is also an essay which is regularly referenced as the source of many of the standard interpretations of Veblen's understanding of these terms, not least by members of the old or original instititionalist tradition that regularly claims Veblen as its figurehead. The essay was published when Veblen was aged 52, and likely at the height of his intellectual capacities, with his philosophical orientation likely reasonably settled. It appeared 10 years after his formative Theory of the Leisure Class: An Economic Study of Institutions (1899a), and the body of his methodological essays on evolutionary thinking; and 5 years even after his Theory of Business Enterprise (1904), at a time when his philosophical ideas were perhaps as worked out as they ever were.

In due course I compare the position found in this contribution with that manifest in an earlier text that is also relatively explicit and sustained on the issues here of interest. This is a particular chapter of his earlier The Theory of the Leisure Class, published in 1899, but possibly written at least in part well before that. I shall suggest that there is indeed evidence that Veblen's thinking on the issues that concern me here developed significantly over the period between the two publications. I shall, as I say, also examine other texts, including later works, necessarily somewhat abstractly and selectively, to see if anything more can be said about the relevant ontological features that I identify as having developed over time.

To ease the exposition I shall often refer to the later of the two contributions on which I most focus as the Marginal Utility essay (or the 'later essay'), and to the earlier of the two as the Leisure Class (or the 'earlier text').

It is to the Marginal Utility essay that I turn first of all then. However before seeking to understand the relevant ontological conceptions and preconceptions of Veblen's analysis contained within it, I think it is important briefly to give some context, and in particular to signal the scope of his analysis, the range of material with which Veblen is mainly concerned, at least in this essay. It is thus by outlining the latter that I start.

\section{Veblen's focus}

A first point to emphasis is that Veblen's subject-matter is systematically bounded in various ways. It is limited, first of all to the topic that Veblen regards as the proper concern of

\footnotetext{
${ }^{2}$ Of course, the issue of change versus continuity in a contributor's thinking is a prominent one in debates within the history of economics. It figures especially in discussions of Smith, Ricardo, Marx, Marshall, Keynes and Hayek. To my knowledge Veblen has been treated less frequently or sympathetically in this regard; the running together of snippets out of context seems especially common. Of course there are notable exceptions, with some contributors being especially keen to assess the degree of development and change over time. A good example of the latter is provided by Janet Knoedler and Anne Mayhew (1999) in analysing Veblen's treatment of the engineering professions. In the current paper, in any case, the focus is on the ontological conceptions/presuppositions of ontological thinking specifically, and I adopt the strategy noted.
} 
economics specifically, namely "the conduct of man in his dealings with the material means of life" (Veblen, 1909, pp. 627-8). Second, within the latter, the subject-matter is further limited to the broader sweep of social development, turning on such factors as habitual activity, processes of habituation, and cumulative changes in the fabric of human culture. In restricting himself to the latter, Veblen declares himself to be not especially interested in specific instances of how people meet their short term goals, or what he terms the "teleological details of conduct" (ibid, p. 626).

That said, Veblen does not deny the fact of teleology in the details of human conduct, though he is highly critical of the manner in which advocates of marginal utility economics make this their sole focus (ibid, p. 262). But human conduct in general, Veblen insists, is far broader than this and, in particular, is also subject to the sequence of cause and effect that proceeds (as we shall see) by way of such factors as habituation and conventional requirements. In Veblen's assessment the "facts of this order [...] are to modern science of graver interest than the teleological details of conduct" (ibid, pp. 626-7).

Veblen is convinced that in "so far as modern science inquires into the phenomena of life [...] it is occupied about questions of genesis and cumulative change, and it converges upon a theoretical formulation in the shape of a life - history drawn in causal terms" (ibid, p. 627). And in so far as any inquiry into human conduct "is a science in the current sense of the term, any science, such as economics, which has to do with human conduct, becomes a genetic inquiry into the human scheme of life" (ibid, p. 627).

As I say, Veblen's focus is economics, specifically the conduct of 'man' in his dealings with the material means of life. So the scope as noted is restricted; "the science is necessarily an inquiry into the life-history of material civilization, on a more or less extended or restricted plan" (ibid, p. 628). In this Veblen never regards the subject-matter of economics as existing somehow in isolation from the rest of social reality. However, he holds that the focus of economic science will always converge on the scheme of material life; "in so far as the inquiry is economic science, specifically, the attention will converge upon the scheme of material life and will take in other phases of civilization only in their correlation with the scheme of material civilization" (ibid, p. 628).

So economics as science, according to Veblen, ought to deal with causal processes amounting to the life-history of material civilization. It is in this context that categories like institution, habit and the additional notion of habituation (seemingly under-examined by Veblen scholars) come to the fore, and matters relating (explicitly or not) to order and stability, etc., arise. Indeed, 'scientific enquiry' in economics is a concern with human conduct only in those respects that it bears on processes of habituation and the development of, or conditioning by, institutions:

"Scientific inquiry in this field, therefore, must deal with individual conduct and must formulate its theoretical results in terms of individual conduct. But such an inquiry can serve the purposes of a genetic theory only if and in so far as this individual conduct is attended to in those respects in which it counts toward habituation, and so toward change (or stability) of the institutional fabric, on the one hand, and in those respects in which it is prompted and guided by the received institutional conceptions and ideals on the other hand" (ibid, pp. 629-30). 
Notions of institutions and habituation are, then, fundamental to understanding Veblen's ideas about the conditions of a developing material order, at least as they are found in the Marginal Utility essay. As such, for Veblen, they are a proper focus of any science of economics. My primary concern is to distinguish the nature of the notion of social order that seems to underpin Veblen's numerous assessments of the proper focus of economic science. What is this order such that the "facts of this order [...] are to modern science of graver interest than the teleological details of conduct" (ibid, pp. 626-7). As a preliminary to addressing this question it is obviously necessary to first be clear about Veblen's understanding of categories like institutions, habits and habituation that are identified as being so essential to the relevant broader integrated picture.

\section{Veblen on institutions}

I start with Veblen's interpretation of an institution. As noted, if there is a text or paper in which Veblen is widely acknowledged to provide his most insightful analysis of all such categories as habits, institutions and habituation, it is seemingly The Limitations of Marginal Utility (Veblen, 1909). Certainly this is a highly insightful contribution. And it is indeed a specific passage or extract from this contribution that is reproduced on seemingly most occasions where Veblen's definition of an institution is said to be given.

Before turning to this specific passage, though, I want to consider some other passages of the Marginal Utility essay that include statements about institutions, to indicate the manner in which he interprets them.

In talking about the school of marginal utility economists Veblen talks of institutional facts and the inability of that school to deal with an institution or any institutional phenomenon interpreted as elements of the cultural fabric:

"It is characteristic of the school that wherever an element of the cultural fabric, an institution or any institutional phenomenon, is involved in the facts with which the theory is occupied, such institutional facts are taken for granted, denied, or explained away" (ibid, p. 632)

In further discussing institutional features that are so treated as either given, denied or explained away Veblen references "human relations governed by use and wont" along with "ownership and free contract, together with such other features of the scheme of natural rights as are implied in the exercise of these" (ibid, pp. 623-4)

Elsewhere in the essay Veblen writes of 'institutional norms' (p. 629); the institutional character of an 'individual's [...] habitual relations to his fellows in the group' (p. 629); the 'institution of ownership' (p. 630); the 'definitive nineteenth-century institution' of property ownership (p. 630); '(prevailingly) institutions of the price system' (p. 631); 'Pecuniary institutions [that] induce pecuniary habits of thought' (p. 632); 'the institutional scheme of the price system'(pp. 632-3); and he includes assessments of the form: 'Like all human culture this material civilization is a scheme of institutions - institutional fabric and institutional growth' (p. 628); and so on.

My own inclination was initially to interpret these passages as referring to features of social reality that, though obviously dependent on human being and interaction, are ontologically and causally irreducible to human agency and conduct (e.g. Lawson 2003a, 2003b, and 
especially 2004[2015]). That is I did not regard institutions as being purely ideational, or mentalistic.

But the passage which seemingly is most explicit in its elaboration of institutions in the Marginal Utility essay, the one which most Veblen scholars regularly interpret as providing his definition of institutions, is more difficult to reconcile with such a non-reductionist perspective. This famous passage runs as follows:

"That is what is meant by calling them institutions; they are settled habits of thought common to the generality of men" (ibid, p. 626).

Strictly speaking, however, this is not a definition at all. Not only the term 'them' in the first clause but also the term 'they' in the second, reference something not actually mentioned in the sentence. Rather the referent of both these terms turns out to be the premises of marginalutility economics. So Veblen is not so much defining institutions as explaining why he is interpreting these premises of marginal utility economics as institutions, namely because they possess the property of being settled habits of thought common to the generality of men.

So there is an ambiguity here, at least in this central passage. It is not clear from this conjoint sentence alone whether institutions just are settled habits of thought common to the generality of men, or the latter are included in this category but not necessarily constitutive of it. In other words, the intended meaning could be either 1) that habits of thought, when widespread and settled, are just an example of institutions (where an institution per se is any social phenomenon that is relatively enduring or settled and widely adhered to; or 2) that institutions are constituted as habits of thought (if specifically those that are settled and prevalent).

In previous assessments (Lawson, 2003b, 2004 [2015]) I have defended interpretation 1). But I now accept that I was mistaken, and that 2) is the correct interpretation of Veblen on these issues. The reason's I (wrongly) accepted interpretation 1) no doubt include the fact that the conception of social ontology I elsewhere defend is more consistent with 1). That is, I defend an account of social reality that has a greater practical dimension, and where social structures include emergent totalities (like capitalism itself) that are not always well understood, or uncontested, let alone purely ideational (though of course always dependent on human conceptions). I have used the term institution where any such social structure, however little understood, is regarded as being relatively enduring (see e.g. Lawson, 2003a, 2004 [2015]). As a result, being both an admirer of Veblen's writings and in agreement with much of it, I likely too easily committed the common, if cardinal, sin of assuming too quickly that we hold in common more than is the case; on treating agreement as a default position. ${ }^{3}$ In addition, not all contributors to the institutionalist tradition have presented Veblen's ontology as ideational; some influential contributors indeed have presented it as being very similar to the conception that I defend. I was perhaps also too uncritical of these accounts, at least on this issue, and again for the reason given above of wanting us all to be of the same assessment.

Why have I changed my view? Given there is ambiguity in the Marginal Utility essay I examined the vast corpus of Veblen's writing focussing specifically on his use of the category institution, and was forced to conclude (as I must admit most historians of thought

\footnotetext{
${ }^{3}$ By acknowledging that our positions are after all not identical, I am not suggesting that Veblen's position, because produced in an earlier era, must for that reason be any less sustainable than my own. Indeed, if I am now interpreting it correctly Veblen's notion of institution is seemingly very similar to that currently defended, for example, by John Searle (e.g., 2010). For a comparison of Searle's position and my own on this and related issues see Lawson 2014.
} 
have before me) that Veblen is overall very clear and consistent that, for him, institutions are (settled) habits of thought. This, of course, is also in keeping with the fact that Veblen early on was somewhat significantly influenced by Kant.

Though I cannot of course do much more than report this finding and assessment, I can reproduce a few suggestive passages to back it up.

For example, in a paper published at more or less the same time as the Marginal Utility essay Veblen writes of:

"the principles of Christian morality or of pecuniary competition [which] must, like any other principles of conduct, be taken simply as prevalent habits of thought. And in this light no question can be entertained as to the intrinsic merit, the eternal validity, of either. They are, humanly speaking, institutions which have arisen in the growth of the Western civilization" (Veblen, 1910, p. 170)

In his earlier The Theory of the Leisure Class: An Economic Study of Institutions 1899, Veblen writes:

The institutions -- that is to say the habits of thought -- under the guidance of which men live [....] These institutions which have thus been handed down, these habits of thought, points of view, mental attitudes and aptitudes, or what not [...]" (Veblen, 1899, p. 191) ${ }^{4}$

And in his later Instinct of Workmanship of 1914 Veblen writes for example:

"There being little in hand worth owning and little purpose to be served by its ownership, the habits of thought which go to make the institution of ownership and property rights have not taken shape" (ibid, p. 143).

And so on.

If we accept that institutions are but habits of thought, an obvious question to raise is how this interpretation can be reconciled with the earlier noted passages of the Marginal Utility essay where Veblen seemingly allows that institutions, or institutional elements, include norms, relationships, property and so on?

\footnotetext{
${ }^{4}$ Elsewhere in the same text Veblen writes:

"The situation of today shapes the institutions of tomorrow through a selective, coercive process, by acting upon men's habitual view of things, and so altering or fortifying a point of view or a mental attitude handed down from the past. The institutions -- that is to say the habits of thought -- under the guidance of which men live are in this way received from an earlier time; more or less remotely earlier, but in any event they have been elaborated in and received from the past" (1899, pp 190-1)

And also:

"At the same time, men's present habits of thought tend to persist indefinitely, except as circumstances enforce a change. These institutions which have thus been handed down [...]" (ibid, p. 191)

And again:

"These institutions which have thus been handed down, these habits of thought, points of view, mental attitudes and aptitudes, or what not, are therefore themselves a conservative factor" (ibid, p. 191)

And further:

"Any community may be viewed as an industrial or economic mechanism, the structure of which is made up of what is called its economic institutions. These institutions are habitual methods of carrying on the life process of the community in contact with the material environment in which it lives" (ibid, p. 193)

And so on. Interestingly a journal referee questioned whether the reference to methods in the last passage render the habits in question other than habits of thought. But I think not. I read Veblen as suggesting that habits of thought amount to methods for, in the sense of principles to guide members of a community in, carrying on the life process.
} 
Bearing in mind his Kantian training, Veblen likely means something like the following. Loosely speaking habits of thought are, in content, ways and means (including strategies, assumptions, categories, principles and so forth) of thinking and processing information whereby individuals seek to make sense of, and act capably in, the world around them, where each of these is regularly triggered in appropriate conditions.

Of course, institutions, though (on this interpretation) comprised of habits of thought, are not any old such thought processes that have become habitual and settled, but those that are also prevalent being 'common to the generality of men' in some context. In other words, an individual cannot create an institution for him or herself, just as a group cannot create one merely for a day; they have to be relatively enduring or settled and common to all members of some group, repeatedly providing the accepted grounds for (other forms of) activity or conduct. Still, on the interpretation in question, they remain entirely ideational in nature.

Consider again the passage often thought to be definitional of Veblen's idea of institutions, but considered now in its broader context:

"There is, therefore, no call to impugn these premises of the marginal-utility economics within their field. They commend themselves to all serious and uncritical persons at the first glance. They are principles of action which underlie the current, business-like scheme of economic life, and as such, as practical grounds of conduct, they are not to be called in question without questioning the existing law and order. As a matter of course, men order their lives by these principles and, practically, entertain no question of their stability and finality. That is what is meant by calling them institutions; they are settled habits of thought common to the generality of men" (ibid, p. 626).

Habits of thought, here, then, include or cover principles repeatedly acted upon; the latter being objects of thought. And the term "That" which opens the familiar sub-passage refers to the fact that people live by "these principles and, practically, entertain no question of their stability and finality".

If institutions include human relations governed by use and want, property, and so on, how do, or could, these notions fit with the idea of institutions as prevalent habits of thought? Ultimately property is constituted via principles, as are the (other) rights and obligations that might be said to be the components of social relations in general (see e.g., Lawson 2012a, $2012 b$ ). There is a sense in which all, in the end, are bound up with (are, or give rise to, or presuppose) ways, and means and strategies and principles of conduct, so may exist in some form, at least according to Veblen's thinking, as, and indeed as being constituted through, the settled habits of thought that are prevalent ${ }^{5}$.

So it is possible to reconcile all of Veblen's various comments on institutions under the idea that, in nature, they are merely ideational and specifically actually defined as settled and prevalent habits of thought.

\footnotetext{
${ }^{5}$ This is consistent at least with Veblen's formulation in the The Theory of the Leisure Class: An Economic Study of Institutions where he writes:

"The institutions are, in substance, prevalent habits of thought with respect to particular relations and particular functions of the individual and of the community; and the scheme of life, which is made up of the aggregate of institutions in force at a given time or at a given point in the development of any society, may, on the psychological side, be broadly characterized as a prevalent spiritual attitude or a prevalent theory of life" (1899, i, p. 190)
} 
Moreover additional support for this interpretation is provided elsewhere in the Marginal Utility essay where institutions are frequently included as part of the community's, or group's 'scheme of life', or 'theoretical schemes', as though such schemes are ideational features held in common by all members of the relevant party ${ }^{6}$.

Thus Veblen writes of "The cultural elements involved in the theoretical scheme, elements that are of the nature of institutions" (p. 623) (notice the term 'involved' rather than say 'posited' or 'referenced'); of "scientific inquiry into the nature, origin, growth, and effects of these institutions and of the mutations which they undergo and which they bring to pass in the community's scheme of life" (p. 627); and so on ${ }^{7}$.

In short, institutions, for Veblen, are purely ideational, referring in effect to theoretical schemes involving (habitual) principles and strategies of action. On a quick reading the usage can appear metaphorical, but ultimately, taking into account the wider reach of his writings in their context, it seems clear that Veblen interprets the term literally. Cultures, including institutions, are theoretical schemes for going on in life ${ }^{8}$.

\section{Veblen's Dichotomy?}

If institutions are relatively enduring or 'settled' does this mean that they are relatively stable? If so how do they impart this stability? I will argue below that the source of societal stability lies elsewhere, at least according to Veblen in his essay on Marginal Utility, and in particular in traits of human nature. For now, though, I want to consider the claim widely found within institutionlist thinking that institutions are not merely stable but more or less fixed, and indeed are effectively constitutive of that which is stable in social life.

The manner in which this claim is typically made is as a component of an analytical principle often referred to as the 'Veblenian dichotomy'. This refers to the idea, associated with Veblen, that as an analytic device institutions and technology are to be treated in a somewhat

\footnotetext{
${ }^{6}$ Those familiar with the contributions of John Searle (e.g., 2010) may detect a further similarity of perspective, not least with his ideas of institutional facts, resting on collective intentionality.

${ }^{7}$ Other passages of the Marginal Utility essay supportive of this interpretation include:

"Since the response that goes to make up human conduct takes place under institutional norms and only under stimuli that have an institutional bearing; for the situation that provokes and inhibits action in any given case is itself in great part of institutional, cultural derivation. Then, too, the phenomena of human life occur only as phenomena of the life of a group or community: only under stimuli due to contact with the group and only under the (habitual) control exercised by canons of conduct imposed by the group's scheme of life" (ibid p. 629)

"It is, of course, on individuals that the system of institutions imposes those conventional standards, ideals, and canons of conduct that make up the community's scheme of life" (ibid p. 629) 631).

"Economic institutions in the modern civilized scheme of life are (prevailingly) institutions of the price system" (ibid p.

"Although the institutional scheme of the price system visibly dominates the modern com-munity's thinking in matters that lie outside the economic interest, the hedonistic economists insist, in effect, that this institutional scheme must be accounted of no effect within that range of activity to which it owes its genesis, growth, and persistence" (ibid p. 633)

"If, in fact, all the conventional relations and principles of pecuniary intercourse were subject to such a perpetual rationalized, calculating revision, so that each article of usage, appreciation, or procedure must approve itself de novo on hedonistic grounds of sensuous expediency to all concerned at every move, it is not conceivable that the institutional fabric would last over night (ibid p. 636).

${ }^{8}$ Veblen does though reference 'habits of thought' on one other occasion in the Marginal Utility essay. He writes:

"Pecuniary institutions induce pecuniary habits of thought which affect men's discrimination outside of pecuniary matters; but the hedonistic interpretation alleges that such pecuniary habits of thought do not affect men's discrimination in pecuniary matters" (ibid p. 632).

I take it that here Veblen is merely saying that settled and prevalent habits of thought in one domain (the pecuniary) can bring about similar habits of thought in another domain. If this is so, this usage is consistent with the ideational interpretation of institution with which I am working. Of course it does not follow that pecuniary habits must cross domains. Habits can remain domain specific even within a given community; we find inconsistency everywhere.
} 
dichotomous fashion, with the former regarded as synonymous with constraint, rigidity, or stasis and the latter associated with change and dynamics ${ }^{9}$.

According to those who accept the dichotomy, social life, or more specifically culture, is, as I say, decomposable into two components: technology and institutions. Or rather it is decomposable into technology and the ceremonial features of life, where prominent among the latter are institutions. And these two components are interpreted as very different indeed. The former serves as a continuous internal impulse to change, without technology there would be no change; the latter acts merely to constrain, to render everything static.

As is well known, institutionalists who take the view described draw significantly on the (early) writings of Clarence Ayres in particular ${ }^{10}$. But it is a position popularised especially by David Hamilton, particularly in his endeavour to explain the supposed "enigma" of social life, that it, including especially culture, reveals both continuity and change. His explanation is simply that technology provides the latter while institutions impose the former:

"Once this distinction is clearly seen, the seeming enigma of the dynamic and static aspects of culture becomes clear. Culture is made up of dynamic and static elements that appear "in some sort of symbiosis." Veblen and other institutional economists call the static element institutions; the dynamic element is called technology" (Hamilton, 1991, p. 84).

According to this conception institutions (and related ideas like 'institutional patterns') are said to be static, or rigid, because they are enforced by a system of authority, one that is not open to critical examination ${ }^{11}$.

These ideas are said to be Veblen's, but what actually does Veblen himself have to say on these matters? Or at least what does he say in the Marginal Utility essay? Clearly, he sees change as endemic to the nature of social reality as a whole. Everything, or everything of interest to science, is a process of cumulative causation. Certainly technology contributes to this. But so potentially does everything else, including institutions. There is no real dichotomy present. Thus immediately following the very passage in which Veblen appears to suggest that institutions are settled habits of thought, he writes:

"But it would be mere absentmindedness in any student of civilization therefore to admit that these or any other human institutions have this stability which is currently imputed to them or that they are in this way intrinsic to the nature of things. The acceptance by the

\footnotetext{
${ }^{9}$ A practical reliance upon the dichotomy in question has been most apparent within the dominant North American strand of institutionalist thinking, with some contributors even prepared to argue that it constitutes the tradition's central analytic tool or defining core (see, e.g., Waller 1982; Munkirs 1988; Klein and Miller 1996). However, not all institutionalists have accepted the dichotomy as formulated, even within the North American movement. Indeed over time there appears to be a significant amount of dissent within this grouping (see, e.g., Ramstad 1995; Wisman and Smith 1999) as well as endeavor to reformulate aspects of the dichotomy (see, e.g., Tool 1979; Miller 1992; Bush 1987, 1989; Waller 1987; Dugger 1995). ${ }^{10}$ For whom the following summary statement is perhaps characteristic:

"The history of the human race is that of a perpetual opposition between ... the dynamic force of technology continually making for change, and the static force of ceremony — status, mores, and legendary belief_opposing change." (1944, 176)

11 Thus according to Hamilton:

"What makes institutions static is the fact that the ultimate test of authenticity for any institutional pattern rests on authority - the authority of magic, religion, habit, and custom reinforced by a mythical efficacy. The institutional pattern is tied closely to the system of status of the community to which is attributed great significance. All groups have been graded into positions of higher and lower status in accordance with an imputed efficacy to perform feats of prowess, whether religious, military, pecuniary, or scientific". (Hamilton 1991, p. 84).
} 
economists of these or other institutional elements as given and immutable limits their inquiry in a particular and decisive way. It shuts off the inquiry at the point where the modern scientific interest sets in" (Veblen, 1909, pp 626-7).

Rather the proper goal of scientific inquiry is "into the nature, origin, growth, and effects of these institutions and of the mutations which they undergo and which they bring to pass in the community's scheme of life" (ibid, p. 627)

But if institutions are not given and immutable, meaning that social reality in all its forms is subject to cumulative change, seemingly rendering any notion of a Veblenian dichotomy misplaced, does anything contribute at all significantly to stability across such changes as occur? As I say, I think that, at least at the time of his writing the essay on Marginal Utility, the main source of stability is viewed by Veblen as stemming from traits of human nature (see below), and specifically from the conditioning effects of the latter on conduct. This consideration takes us to Veblen's notion of habituation. However, before it is possible to analyse this idea it is necessary to be clear on Veblen's conception of habit. It is thus to a consideration of the latter category that I now turn.

\section{Veblen's notion of habit}

What, then, does Veblen mean by habit? Of course I have already had to adopt a preliminary stance on this in entertaining the idea that, for Veblen, institutions are defined as forms of habits of thought. Implicitly, in this, I took habits to be features of human conduct or activity (in the case of institutions, the activity of thinking) concerned typically with other (not merely mental) forms of conduct. What makes these (prevalent) forms of thinking habitual is that they are settled and automatically triggered in appropriate conditions; they do not constitute processes of constant deliberation. More generally, now, I take all kinds of habit (not merely habits of thought) to be forms of behaviour or conduct repeatedly carried out, being triggered, usually subconsciously and unquestioningly, by relevant conditions.

There is however a contrasting interpretation to this that is seemingly popular in sections of the institutionalist literature. This holds that Veblen uses the term habit to denote (or also to denote) human dispositions, propensities, proclivities and even capacities. Let me elaborate these notions a little.

I do not think there is disagreement amongst the various interpreters of Veblen as to how notions of capacity and disposition, etc., are most appropriately interpreted; the disagreement is rather over whether term habit is to be equated to (or to include) them.

A capacity, I take it, is a (perhaps acquired) ability or potential to achieve something, including perhaps a particular form of conduct. And whatever the conditions that come about, a capacity either may or may not be exercised or brought to bear. Thus the hall has the capacity to seat 1000 people even though only four turned up. Or I believe myself have the capacity to study all day and night though I have decided not to study at all.

Terms like dispositions, proclivities, propensities, and (in this context) tendencies, though differently nuanced, refer to inclinations to certain forms of conduct, if triggered.

Clearly, although I believe it both unhelpful, and not Veblen's strategy, to equate habit to capacity or inclination, I do not deny, of course, that the three types of features (capacities, 
inclinations, and habits) inter-relate. A British person B may, for example, have 1) the (acquired) capacity (or better capability) to speak French, whether or not B ever exercises it, even when visiting France; 2) the inclination (disposition, propensity, tendency), to exercise this capacity if needed in France, but to avoid speaking French outside of France or anywhere where so doing appears pretentious; and 3) the habit, when speaking French, of (erroneously) addressing everyone as 'tu'. Clearly the capacity in question is a condition for the noted inclinations or dispositions as well as the (bad) habit, but they do different jobs.

Perhaps most importantly, the possession of a capacity indicates nothing about its likely actualisation (an individual may have the capacity to kill, or fast for a week, or to throw a brick through a neighbours window, where all remain forever unrealised). A propensity or disposition, in contrast, tell us more about the individual, so that if certain circumstances come about, a form of behaviour would not be especially unusual (for example a British person holding back on speaking French, say, in conditions where others may regard it as showing off).

Although such inclinations (propensities and dispositions) are features of human nature that ultimately underpin relative continuity and stability in social life, they are less directly implicated in this and are far more subject to conscious control than is the form of passive conduct that I am calling habit. Of course, if we reflect enough we can focus on habits too, and if we work hard enough at it we can usually eventually change habits interpreted as forms of conduct, with time; or circumstances may force us to anyway, if existing habits cannot be sustained. But typically a habit is a form of conduct that is regularly automatically triggered in 'appropriate' conditions.

I can think of no good reason why Veblen would want to use these categories interchangeably; nor can I find any evidence that he does so; certainly I am not aware of any reason or evidence that he should take habit to mean a capacity or inclination. Yet, as I say, the belief that he does seems to be promoted in strands of modern institutionalism. Geoffrey Hodgson, for example writes as follows:

"However, there has been some ambiguity in the definition of habit. Veblen and the pragmatist philosophers regarded habit as an acquired proclivity or capacity, which may or may not be actually expressed in current behavior. Repeated behavior is important in establishing a habit. But habit and behaviour are not the same. If we acquire a habit we do not necessarily use it all the time. A habit is a disposition to engage in previously adopted or acquired behavior or thoughts, triggered by an appropriate stimulus or context" (2006, p. 6)

Here Hodgson talks of 'using' a habit as though it is identical to a capacity (say to speak French). Though I do not really find this a compelling notion, I recognise the issue here is not coherence per se but the interpretation of Veblen. Elsewhere Hodgson writes:

"For James, Veblen and Dewey, habit was a propensity or disposition. It did not mean behaviour as such. James (1893, p. 143) proclaimed: 'Habit is thus the enormous flywheel of society, its most precious conservative agent.' Veblen (1898a, p. 390) wrote of a 'coherent structure of propensities and habits which seeks realisation and expression in an unfolding activity'. Veblen (1898b, p. 188) also remarked that 'man mentally digests the content of habits under whose guidance he acts, and appreciates the trend of these habits 
and propensities.' As Dewey (1922, p. 42) put it: 'The essence of habit is an acquired predisposition to ways or modes of response' " (Hodgson, 2004, p. 652)

It is actually not at all obvious from these passages (to this observer at least) that James or Dewey (any more than Veblen) are here equating a habit to a propensity or a disposition. But more to the point, Hodgson is presumably running together the pragmatist philosophers William James (1842-1910) and John Dewey (1859-1952) with Veblen, in order to imply that whatever the conceptions of habit(s) held by the latter two the same must also have been held by Veblen.

This observation has only to be stated for the lack of force of such a strategy to be appreciated. No more than we can assume that Marx meant by dialectic the same as Hegel, or by labour the same as Adam Smith, or that, by classical economy, Veblen meant the same as Marx, or even indeed that the institutionalists Ayers, Mitchell and Commons interpret their central categories identically, can we just suppose that with habit, Veblen meant the same as James or Dewey (whatever were their interpretations of the term). The case for shared meaning needs to be made rather than merely presumed and thereby used as a means to determine Veblen's understanding.

Hodgson does additionally give two passages where Veblen uses the terms habits and propensities in the same sentence. But in both cases the two terms are, it is significant to note, separated by the conjunction 'and'. This is hardly convincing as evidence that Veblen thought of the notions as identical. Hodgson continues the latter noted passage as follows:

The mechanisms of habit are largely unconscious, but they may press on our awareness. Habits are submerged repertoires of potential behaviour; they can be triggered or reinforced by an appropriate stimulus or context. The meaning of habit adopted by Veblen, the pragmatist philosophers and instinct psychologists was of an acquired proclivity or capacity, which may or may not be actually expressed in current behaviour. Repeated behaviour is important in establishing a habit. But if we acquire a habit we do not necessarily use it all the time. It is a propensity to behave in a particular way in a particular class of situations." (Hodgson, 2004, p. 652)

The first the fourth sentences are unproblematic. But the third sentence I dispute, at least as applied to Veblen. Though habits do of course presuppose acquired proclivities and various capacities, these per se do not constitute the 'meaning of habit'. Habits are repeated forms of conduct, triggered in relevant conditions. Or at least, this is the position I intend to defend.

With all this in mind let me for now proceed by examining the evidence thrown up by Veblen's essay on The Limitations of Marginal Utility specifically. Perhaps it is worth observing first of all that the terms capacities, proclivities, inclinations, tendencies and the like never appear at all in this essay. The question, then, is whether the category habit does all the work they usually do.

As it happens the term habit, or a similar one with habit as the stem, appears 28 times and, whilst Veblen's usage is variable, I can find no instance where use of the relevant term easily lends itself to meaning capacity, proclivity, propensity or disposition and so on, at least as these latter categories are usually interpreted, including, seemingly by Hodgson. 
The situation is in fact as follows. There are numerous occasions where a derivative of the term is used as an adverb, to indicate how the conduct is manifest (i.e., habitually) as in "habitually profess" (p. 622), "habitually made use" (p. 632), "it is habitually made" (p. 633)," habitually not contemplated (p. 634)", "habitually aspire to accumulate" (p. 634), etc.

There are equally many occasions where a related term is used adjectively to characterise a feature of actual conduct (i.e., that it is habitual), such as when Veblen uses expressions like "the habitual activity of mankind" (p. 627), "habitual response" (p. 628), "habitual manner of response" (p. 628); "habitual or conventional canons of conduct or standards of valuation" (p. 631); "Money and the habitual resort to its use" (p. 633).

I can find no instance, however, where any such term is used to qualify a trait of human nature (say, rendering a potential a capacity, or a capacity a disposition).

There are also various usages of the term 'habitual' that at first sight appear to qualify neither conduct nor traits of human nature, as when Veblen makes reference to such phenomena as an individual's "habitual relations" (to his fellows in the group) (p. 629); "habitual standards and ideals" (p. 630); "habitual or conventional [...] standards of valuation" (p. 631); "habitual grounds of discrimination" (p. 632); "the growth and change of these habitual, conventional elements make the growth and character of any business era or business community" ( $p$. 635). If on reflection it remains difficult to see how these can refer to capacities, etc., that may or may not be operative, it is easy enough to see how they may mean forms of conduct regularly activated. Thus 'habitual relations' presumably means 'relations habitually entered into', 'habitual standards and ideals', means standards and ideals habitually adopted'; and so on.

At least as insightfully (putting frequency of instances of use aside), I might consider again the central point of the essay on the limitations of marginal utility. Veblen is here contrasting the marginal utility approach with the scientific approach of evolutionary theorising. In the economics academy in particular, according to Veblen, to think in terms of, and to apply, the premises of marginal-utility economics is to fall back on settled habits of thought.

Might Veblen mean capacity here, i.e., a capacity for a certain sort of thought or method or reliance on specific principles? Of course we all, Veblen included, have the capacity to think in terms of these premises and for that matter even to adopt them. So if habit merely means capacity then should Veblen be said himself to have the relevant habit (of thought), and so qualify as a member of the marginal utility school?

Or might Veblen mean disposition or propensity here? If so, then it is conceivable that an individual could be inclined towards thinking in these ways and to adopting these premises of marginal utility analysis without actually always doing so; through somehow managing to overcome the disposition or propensity in question on occasion at least and actually thinking instead in terms of the alternative approach of evolutionary thinking. Could this be Veblen's interpretation of habit?

Seemingly not, for he suggests that, for those implicated by the habit, thinking according to other principles never actually happens. Rather, Veblen talks of the premises involved as being accepted tacitly as 'immutable' by those who employ them, not a matter of choice. Instead what is observed is "the acceptance of these immutable premises, tacitly, because uncritically and as a matter of course". They constitute principles of action not to be called 
into question, as non-optional habits of thought that serve in turn to ground the conduct of research endeavour. The hedonists or members of the marginal utility school order their academic life by them, not optionally, or as a disposition, but unerringly as a matter of course. We have already seen all this in Veblen's assessment that these particular habits of thought can be regarded as institutions. Of course, Veblen acknowledges that all institutions do change eventually. But this is not the point. When acting on these habits, the marginal utility economists suppose they are acting on 'principles of action' that 'are not to be called in question without questioning the existing law and order. As a matter of course, men order their lives by these principles and, practically, entertain no question of their stability and finality'. This indeed, 'is what is meant by calling them institutions; they are settled habits of thought common to the generality of men' (Veblen, ibid, p. 626). And, of course, the point is that all inquiry of the marginal utility economists is limited just by the 'acceptance by the economists of these or other institutional elements as given and immutable' (ibid, p. 627) ${ }^{12}$.

\section{Veblen's notion of habituation}

I move on, then, to consider the seemingly less analysed topic of the nature of habituation and its significance to social development according Veblen's thinking. This term, expressing a psychological tendency or process, is much emphasised by Veblen, at least in his essay on Marginal Utility, and is fundamental to understanding the sort of human conduct that most interested him. Indeed habituation is especially important to all of Veblen's thinking at this point in time, not least, or so I will argue, to understanding how traits of human nature underpin relative stability in human society, and the growth of culture more generally. Certainly habituation is a factor in all this. Veblen, indeed, is quite clear in the Marginal Utility essay in proposing that not only "human culture [...] is a scheme of institutions, [...] [but also the] growth of culture is a cumulative sequence of habituation" (ibid, p. 628). Fundamental here is Veblen's assessment that habituation is a significant causal factor bearing upon institutional change and development.

Incidentally, a reason that the category habituation may be under-analysed in parts of the of the current literature is that those few institutionalists who have focussed on the category significantly have by and large rejected Veblen's claims for it. Fundamental here, I suspect, is the influence of (the lectures of) John Fagg Foster ${ }^{13}$. Certainly Foster is dismissive of Veblen's assessments. From the outset, Foster criticises the term incontinent habituation, which he finds in Veblen's account of institutional determination, as 'a very unfortunate phrase'; and he continually insists that "a very little reflection will reveal that [...] habituation is not even possible in the determination of institutions" (Ranson, 2010, p. 109). In Foster's assessment, "Veblen was seeking a theory of institutional adjustment, but precluded himself from it by confusing the content (habits) of institutions with their determination (by discretion)" (ibid, p. 186).

\footnotetext{
${ }^{12}$ Of course, as earlier noted Veblen does in the very next paragraph qualify this by insisting that that all social phenomena, including habits of thought, can and do change. But is a process in time requiring effort; not a mere matter of conscious deliberation regarding when to, or not to, exercise habits as if they are capacities or some such.

${ }^{13}$ Foster taught a good deal, but wrote and published very little and so left mostly an oral legacy. Many institutionalists, though, have been significantly influenced by his oral contributions. Baldwin Ranson has collected together the available works of Foster, including his various written-up lectures, and actively disseminated them. This collection has also been edited and systematised by Ranson in 2010 as John Fagg Foster's Contribution to Scientific Enquiry. My references to Foster are drawn from the latter, so that passages by Foster but denoted (Ranson, 2010, p. x) will refer to page $\mathrm{x}$ of Baldwin Ranson's edited collection. The collection can be downloaded from: http://jfaggfoster.org/FosterByRanson.pdf
} 
Suffice it to say here that Foster's seems to have misunderstood the meaning of the term habituation both as it is employed in the broader literature and by Veblen. Foster is not always clear but seems to interpret the notion of habituation as something like collectively doing things habitually or as collective conduct that is habitual. With the emphasis on such collective habitual behaviour Foster argues that the latter can neither initiate new behavioural patterns which he associates with institutions, nor cause those behavioural patterns associated a collective habitual behaviour, for the latter two emerge simultaneously ${ }^{14}$.

Whatever the precise nature of Foster's understanding, the term habituation, at least in the wider psychological literature, has long had a more specific interpretation. Here, it refers not to a process of doing things habitually but rather to one wherein there is a gradual decline of a response to a stimulus, resulting from repeated exposure to the stimulus. It is this process or tendency, I will suggest below, that is also Veblen's understanding of the term.

We are surrounded constantly by noises, visual signals, smells and so on, all of which can and do change. We could not possibly act continuously as we do if we reacted with conscious awareness or even instinctively to them all; we do not have the capacity or the energy to do so. Instead the human organism, like all others, has evolved the ability to become desensitised to those features of any situation that are found to be, or are interpreted as being, not harmful. We filter out those features or elements of our environment that do not require attention in order to be able focus on those that do. This process of (non-associative) desensitisation is the more typical meaning of the term habituation. We simply stop noticing aspects of the environment that are considered to be not harmful.

If we focus on the social world specifically, a starting point is that this too, of course, is constantly changing. Much day-to-day practical conduct is habitual. And as the exigencies of life change with transformed situations so we need to adapt our habits. In so doing, we habituate to aspects of the various transformed situations that we do not need to constantly readdress anew. Thus culture grows through a cumulative sequence of habituation in responses to changing exigencies that are beyond our control.

An example of habituation, so understood, might occur with the coming into service of a newly constructed railway line that at one point passes close to some residential buildings. Let us suppose that trains are parked and cleaned overnight, but start running very early every morning. On the very first morning on which they run we can imagine various individuals who happen to live close to the line being involuntarily woken by the unfamiliar sounds. However, as time passes, and the sounds become familiar we can equally imagine at least some of these same individuals becoming used (habituated) to the noises in question and

\footnotetext{
14 Thus Foster for example writes:

"The causal sequences involved and the determination of a pattern of behaviour -- an institution -- necessarily require initiation, and usually involve an antithesis between this so called corollary and the mores principle. Initiation requires purposeful behavior, the making of a choice and, thus, the involvement of value theory. The constitution of the mores being habitual -- commonly accepted, as we put it -- they could not determine the initial action. And if it isn't habitual, it dead certain can't be incontinent. It involves making choices. The initial action requires choice and choice involves reason. Institutions are in fact initiated out of actions which are themselves efforts to solve problems. They are not and cannot be incontinent habituation. They become accepted only when they become habitual. Otherwise they would not have any prescriptive force, without which we do not even allow a deliberate specification of a pattern to be called an institution" (ibid, 109-110).

In this passage Foster's rejection of the idea of a process being one of incontinent habituation seems to involve him arguing first against a form of action being not incontinent and then against it being habitual, as if habitual conduct and habituation are identical. Foster also talks of an institution attaining a status of habituation, and of this happening after it has been 'accepted' as habitual. So habituation and collective habitual conduct seem to be roughly the same thing.
} 
sleeping through them. It is this process of the gradual decline in response to a stimulus resulting from repeated exposure that is the process of habituation. Clearly, in this case, the habituation is indeed sub- or un-conscious or incontinent. Notice too, though this is admittedly a trivial case, that the process of habituation is a causal factor in development of the habitual practice that emerges of local people sleeping through train sounds.

We might also imagine that some of the affected community members find it less easy always to sleep through the train noise, and instead start their daily routines earlier than before. If there are enough in this group that are up and about, it may be, with the passing of time, that a local breakfast cafe and/or a paper shop, say, open(s) earlier than otherwise. After a while this all takes on the form of a conventional or accepted way of life, with the residents in question rising at the early hour even if or when, for some reasons, the trains are not running. Of course if there is a station close by, some who formerly drove to work, may acquire the habit (clearly arising out of a conscious decision in this case) of going by train.

On this conception, habituation is not about the initial response to varying exigencies being of a habitual nature, as Foster imagines that Veblen as saying, but about adjusting individual habits of conduct in the light of the changed situations, and via necessarily individual processes of desensitisation to appropriate transformed features of the environment.

But given that, or where, changes in the environment, affect (as in the railway line example) a community of individuals, then, or so Veblen seems to suppose, individual habits can become generalised or common to a group of people; that is they give rise to institutions. In this way institutions (understood as shared and settled habits of thought) are said to be an outgrowth of individual habits, where the latter themselves are a result of processes of individual habituation. Thus, on this interpretation of the notion of habituation, Veblen can indeed infer that culture grows through a cumulative sequence of habituation in responses to changing exigencies that are beyond our control, the ways and means of which, to repeat, lie in individual habit adjustment, giving rise to shared revised habits of thought or institutions.

This, I am suggesting, is Veblen's position. The growth of culture including of institutions is, in the manner indicated, indeed a cumulative sequence of habituation. We will see that in arguing this case, Veblen takes the view that the traits of human nature that underpin the processes of adjustment are fairly constant. It is because of this that there is consistency in the cumulative process going forward.

Thus, in the essay on Marginal Utility, Veblen writes for example that:

"Like all human culture this material civilization is a scheme of institutions - institutional fabric and institutional growth. But institutions are an outgrowth of habit. The growth of culture is a cumulative sequence of habituation, and the ways and means of it are the habitual response of human nature to exigencies that vary incontinently, cumulatively, but with something of a consistent sequence in the cumulative variations that so go forward -incontinently, because each new move creates a new situation which induces a further new variation in the habitual manner of response; cumulatively, because each new situation is a variation of what has gone before it and embodies as causal factors all that has been effected by what went before; consistently, because the underlying traits of human nature (propensities, aptitudes, and what not) by force of which the response takes place, and on the ground of which the habituation takes effect, remain substantially unchanged" (Veblen, 1909, p. 628) 
Here I take it that when Veblen argues that 'institutions are an outgrowth of habit', the reference to habit means those of individuals. This is not to deny that in turn institutions act back on (in the sense of conditioning) everyday non-mentalistic individual human conduct, including habits, as we will see. But institutions, that is shared and settled habits of thought, grow out of individual habits ${ }^{15}$. And individuals adapt habits to the changing exigencies of the transformed situations that are incontinent or beyond their control. This is all part of, indeed it is described by Veblen as the ways and means of, the process of habituation to changed circumstances.

As the environment changes, bringing new exigencies, so the process of habituation keeps kicking in giving rise to ever revised sets of individual habits. Hence, Veblen insists, the "growth of culture is a cumulative sequence of habituation, and the ways and means of it are the habitual response of human nature to exigencies" that emerge.

Veblen indicates something too about how (social) situations change, about the nature of the varying exigencies: that they "vary incontinently, cumulatively, but with something of a consistent sequence in the cumulative variations that so go forward". The changes are outside our control (are incontinent) but are cumulative in that every outcome reached is a variation of what has gone before it and embodies as causal factors all that has been effected by what went before.

In addition the responses to the changed situations reveal a degree of consistency going forward just because "the underlying traits of human nature (propensities, aptitudes, and what not) by force of which the response takes place, and on the ground of which the habituation takes effect, remain substantially unchanged." Consistency and stability within processes of social development then are due in some part to relatively fixed traits of human nature.

That said Veblen is clear that the sorts of adaptations or variations in the habits that ensue are conditioned by not just traits of human nature, but equally the wider institutional context of any such responses. Any process of habituation, including the factors that stimulate it, and the possibilities for, and constraints on, habitual responses that ensue are always situated; they occur in a context which includes prevailing institutions, amongst which are institutional norms. So the prevailing institutional context, which grew out of, and depends upon, processes of habituation will also act back on those very processes. Thus, according to Veblen:

"an adequate theory of economic conduct, [...] cannot be drawn in terms of the underlying traits of human nature simply; since the response that goes to make up human conduct takes place under institutional norms and only under stimuli that have an institutional bearing; for the situation that provokes and inhibits action in any given case is itself in great part of institutional, cultural derivation" (ibid, p. 629)

Moreover, for Veblen, all aspects of the (ideational) social structure must seemingly be recognised as community properties. Thus, in the passage that immediately follows that just reproduced he writes:

\footnotetext{
${ }^{15}$ It is presumably shared institutions, those common to a group, that certain institutionalists such as William Waller are seeking to capture with the notion of social habits (e.g. Waller, 1988). Waller in fact proposes a typology of habits, and issue I cannot, and do not need to, explore here.
} 
"Then, too, the phenomena of human life occur only as phenomena of the life of a group or community: only under stimuli due to contact with the group and only under the (habitual) control exercised by canons of conduct imposed by the group's scheme of life. Not only is the individual's conduct hedged about and directed by his habitual relations to his fellows in the group, but these relations, being of an institutional character, vary as the institutional scheme varies. The wants and desires, the end and aim, the ways and means, the amplitude and drift of the individual's conduct are functions of an institutional variable that is of a highly complex and wholly unstable character" (ibid, p. 629).

At the same time, to make a final observation on Veblen's thinking at this point, the sort of passage just noted ought not to be read too deterministically. In the Marginal Utility essay Veblen does not consider precisely how new habits are formed or existing ones are adjusted, other than to indicate that they follow on from changing circumstances and accompany processes of habituation. But in a lecture delivered to the Kosmos club a year earlier (Veblen 2008), and in a paper on which it draws of two years before that (Veblen 2006), Veblen emphasises in particular the importance of idle curiosity to human knowledge development.

This is too large topic to do justice to here. But essentially Veblen distinguishes between 'pragmatic knowledge' which is somewhat passive or reactive being expedient, directed or problem solving and 'idle learning' or knowledge which results from idle curiosity, and initiates changes in unanticipated ways. In Veblen's view evolutionary change is always a compound of 'pragmatism' or pragmatic teleological behaviour and the unforeseeable consequences of idle curiosity, even where the latter might meet with resistance ${ }^{16}$. In the era that the Veblen regards as modern idle curiosity underpins science. In a pithy remark Veblen sums up the difference in the two approaches as follows: "Pragmatism creates nothing but maxims of expedient conduct. Science creates nothing but theories" $\left(2006\right.$, p. 19) ${ }^{17}$.

If a reactive determinism is avoided by Veblen in his account of habit formation, so too is voluntarism. Whatever may be the degree of creativity and unworldliness of processes of idle curiosity, the canons of validity that condition any inquiry will always be a product of the cultural situation, of "the scheme of life current in the community in which [the idle thinker] lives" (Veblen 1906, p. 17), whether or not this is recognised by those involved ${ }^{18}$. The processes of habituation and habit adjustment and formation will thus involve both creative disinterested impulses as well as cultural conditioning.

\footnotetext{
16“Idle curiosity creates novelty and makes human culture change — in spite of the resistance of humans" (Anne Mayhew, 1998, p. 455).

17 Veblen continues saying of idle curiosity in the form of science that:

"It knows nothing of policy or utility, of better or worse. None of all that is comprised in what is to-day accounted scientific knowledge. Wisdom and proficiency of the pragmatic sort does not contribute to the advance of a knowledge of fact. It has only an incidental bearing on scientific research, and its bearing is chiefly that of inhibition and misdirection. Wherever canons of expediency are intruded into or are attempted to be incorporated in the inquiry, the consequence is an unhappy one for science, however happy it may be for some other purpose extraneous to science. The mental attitude of worldly wisdom is at cross-purposes with the disinterested scientific spirit, and the pursuit of it induces an intellectual bias that is incompatible with scientific insight" (2006, p. 19).

${ }^{18}$ More expansively, and referring to useful purposes of which idle curiosity knows very little, Veblen observes "These useful purposes lie outside the scientist's interest. It is not that he aims, or can aim, at technological improvements. His inquiry is as 'idle' as that of the Pueblo myth-maker. But the canons of validity under whose guidance he works are those imposed by the modern technology, through habituation to its requirements; and therefore his results are available for the technological purpose. His canons of validity are made for him by the cultural situation; they are habits of thought imposed on him by the scheme of life current in the community in which he lives; and under modern conditions his scheme of life is largely machine-made." (Veblen 1906, p. 17). See also Veblen 1908, especially pp. 38-39.
} 
In short, the habituation of individuals does after all constitute a causal process underpinning the development of Veblen's institutions, affecting their growth and transformations (or mutations); at the same time these institutions simultaneously condition, though do not determine, the relevant conduct of individuals. Foster is in error on various counts, but not least because he seems to work with a less technical notion of habituation.

So much, then, for interpreting notions like institution, habit and habituation, at least as Veblen uses these categories in his essay on Marginal Utility. At this point I have to hand the ingredients to set forth a systematic summary of Veblen's position on the nature of social process, order and stability, at least as held at the time of that essay.

\section{Veblen on order and stability}

In the Marginal Utility essay Veblen makes explicit use of the term order mostly in relation to the presuppositions of the postulates of the school of marginal utility economics. These presuppositions, writes Veblen, confine us to "generalizations of the teleological or 'deductive' order" (p. 622), where the latter, as earlier noted, are "principles of action which underlie the current, business-like scheme of economic life, and as such, as practical grounds of conduct, they are not to be called in question without questioning the existing law and order" (p.626). Veblen, as noted, insists that the marginal utility economists are mistaken in their presumption both of how the social world is ordered and that this order is relatively fixed.

Through this critique, Veblen does reveal his own presuppositions that a social order will indeed be ideational in nature, though very different to a teleological or deductive order, and couched in terms of continuous development. Specifically, the actually existing social order is one "subject to the sequence of cause and effect, by force of such elements as habituation and conventional requirements", so that (as earlier noted) the "facts of this order, which are to modern science of graver interest than the teleological details of conduct, necessarily fall outside the attention of the hedonistic economist, because they cannot be construed in terms of sufficient reason, such as his postulates demand, or be fitted into a scheme of teleological doctrines (ibid, 626, emphasis added by TL).

The community's scheme of life is the basis, the locus, of societal order. And it evolves as individuals repeatedly habituate themselves to uncontrollable changes that render some, or some aspects of, existing habits of thought, that is institutions, inappropriate for actual, and especially habitual, conduct.

As again I have already noted, Veblen is very clear that "institutions are an outgrowth of habit" and that the "growth of culture is a cumulative sequence of habituation, and the ways and means of it are the habitual response of human nature to exigencies that vary incontinently, cumulatively" if somewhat consistently (ibid, p. 628).

I have also noted that stability, including in the form of "a consistent sequence in the cumulative variations going forward", is in some part down to human nature, to the "underlying traits of human nature (propensities, aptitudes, and what not) by force of which the response takes place, and on the ground of which the habituation takes effect, [which] remain substantially unchanged" (ibid, p. 628). 
I have further observed that there are many sources of instability, and indeed that the stabilising human traits are not all determining; conduct always occurs in an institutional context and also within communities, where each community or group can have its own scheme of life ${ }^{19}$. So the institutional factor will have a highly complex and unstable character, as we have also already seen.

The upshot then is the institutional scheme depends ultimately upon the practices of individuals that are members of groups and/or communities, and in particularly on processes of habituation; whilst at the same time the existing scheme of institutions conditions the aims of conduct of all individuals, in constituting in effect the conventional standards, ideals, and principles of conduct that form the community's scheme of life.

Veblen summaries his position, along with its implications for social scientific analysis, as follows:

"The growth and mutations of the institutional fabric are an outcome of the conduct of the individual members of the group, since it is out of the experience of the individuals, through the habituation of individuals, that institutions arise; and it is in this same experience that these institutions act to direct and define the aims and end of conduct. It is, of course, on individuals that the system of institutions imposes those conventional standards, ideals, and canons of conduct that make up the community's scheme of life" (ibid, p. 629)

It follows that science must focus on individual conduct under those aspects either that bear on processes of habituation and so development in the institutional structure, or are conditioned by the latter:

Scientific inquiry in this field, therefore, must deal with individual conduct and must formulate its theoretical results in terms of individual conduct. But such an inquiry can serve the purposes of a genetic theory only if and in so far as this individual conduct is attended to in those respects in which it counts toward habituation, and so toward change (or stability) of the institutional fabric, on the one hand, and in those respects in which it is prompted and guided by the received institutional conceptions and ideals on the other hand" (ibid, pp. 629-30)

So the notion of order that underpins Veblen's analysis in the Marginal Utility essay is an ideational order consisting of theoretical schemes of life and conduct, elements of which are the settled and prevalent habits of thought of the nature of methods, principles of conduct, strategies, and so forth that constitute the institutional elements of a culture. The stability of it all, as an order, is underpinned in particular by those traits of human nature that, via processes of habituation, serve to render all responses habitual in ways that are consistent with the past.

\footnotetext{
${ }^{19}$ Veblen writes: "the response that goes to make up human conduct takes place under institutional norms and only under stimuli that have an institutional bearing; for the situation that provokes and inhibits action in any given case is itself in great part of institutional, cultural derivation. Then, too, the phenomena of human life occur only as phenomena of the life of a group or community: only under stimuli due to contact with the group and only under the (habitual) control exercised by canons of conduct imposed by the group's scheme of life. Not only is the individual's conduct hedged about and directed by his habitual relations to his fellows in the group, but these relations, being of an institutional character, vary as the institutional scheme varies" (ibid, p. 629).
} 
A presumption here (though in the Marginal Utility essay Veblen does not address the issue explicitly) is presumably that such 'underlying traits of human nature', the 'propensities, aptitudes, and what not' that underpin the whole process not only 'remain substantially unchanged' but are fairly uniform across at least groups of individuals. Culture as a whole seems to be an integrated evolving shared ideational fabric in which institutional elements are central, and which conditions, and depends in turn upon, habits of conduct which, like the culture they reproduce, evolve through relatively stable processes of habituation to an ever changing environment.

Though Veblen lacks many of the categories of modern day social ontology, and may have perceived himself as doing something else entirely, I think this account of the social order, if I have interpreted him correctly, constitutes a remarkable contribution in social ontology nonetheless. I now want to contrast this account of Veblen's thinking with that which appears earlier in his contributions to see if there is evidence of significant change including development.

\section{Veblen's earlier conceptions}

A study of Veblen's earlier writings, most especially the methodological essays, reveals more clearly than the Marginal Utility essay just how radical is Veblen's thinking on (evolutionary) process and (cumulative) social change.

Taxonomic science is concerned with normality and regularity, it presupposes normality in or underpinning and grounding the course of events, and Veblen, from (and especially in) his earliest writings, deftly rejects an overly taxonomic emphasis in all its forms. For Veblen a taxonomically oriented approach is misguided whether the 'normality' element is interpreted in terms of tendencies, propensities, being god-driven, or regularity either at the level of actual events or at the level of events when there are no 'disturbing' factors, and so on (see Lawson, 2013c on all this).

In the place of taxonomic science Veblen supports an evolutionary or 'matter of fact' orientation to science which presupposes nothing more than cumulative causal sequence. This contrasts with, and indeed can be said to be the antithesis ${ }^{20}$ of, a taxonomic science.

In the evolutionary case any outcome or event is always caused by something that went before it, but is so not in conformity with some preordained pattern or regularity, nor in a manner serving some normative or laudable purpose, and so forth. Veblen notes in this regard that the evolutionary scientist "is unwilling to depart from the test of causal relation or quantitative sequence" (1898, p. 377), inquiring of everything only "why?", and seeking an answer in terms of cause and effect.

For the taxonomic economist, in contrast, "this ground of cause and effect is not definitive" (ibid, p. 378). Rather the ultimate term in the systematisation of knowledge is something like a 'natural law' or, an association of phenomena, an empirical generalisation, or possibly a correlation regarded as 'natural' or 'normal', or a 'consistent propensity' with any exceptions regarded as mere disturbing factors.

\footnotetext{
${ }^{20}$ Veblen indeed notes of himself that

"In speaking of this matter-of-fact character of the modern sciences it has been broadly characterized as 'evolutionary'; and the evolutionary method and the evolutionary ideals have been placed in antithesis to the taxonomic methods and ideals of pre-evolutionary days" (Veblen 1899b, p.123).
} 
So for Veblen there is little of the form of normality or regularity in the actual course of events. With this opposition to taxonomy being especially prominent in his earlier essays, what did Veblen suggest about the nature of social order in the earlier period, if anything? The contribution that most discusses the issues before us in this earlier period, the only one of which I am aware that is comparable to the essay on Marginal Utility in this regard, is Veblen's (already briefly referred to) The Theory of The Leisure Class, published in 1899, and specifically its chapter 8 . It is this to the latter that I now turn.

\section{The Theory of the Leisure Class}

The first and striking feature to note about this contribution is the frequently use of the phrase 'natural selection'. Whereas in the essay on Marginal Utility evolutionary processes are never stated in such terms, they certainly are in the Leisure Class. Indeed Veblen opens the relevant chapter as follows:

"The life of man in society, just like the life of other species, is a struggle for existence, and therefore it is a process of selective adaptation. The evolution of social structure has been a process of natural selection of institutions. The progress which has been and is being made in human institutions and in human character may be set down, broadly, to a natural selection of the fittest habits of thought and to a process of enforced adaptation of individuals to an environment which has progressively changed with the growth of the community and with the changing institutions under which men have lived" (1899a [1998], p. 188)

Here we immediately observe once more that human institutions are synonymous with habits of thought. A couple of additional features of this passage are also interesting.

First, and in some contrast both to the writings of Darwin and his own more methodological essays of the time, Veblen here interprets such developments as have occurred as 'progress'. Coherent with this, Veblen writes of habits of thought being selected not because they are good or 'fit' enough relative to the environment but because they are the 'fittest'.

Second, Veblen also portrays natural selection processes as working not only on institutions (or habits of thought) but also on underlying traits of human character or nature. Thus, and unlike in the Marginal Utility essay, human nature at this earlier stage is regarded as not fixed but seemingly highly transformable. As in the Marginal Utility essay institutions are both selected and selective. But in this institutions serve to select not merely habitual forms of conduct but also the human beings with the fittest temperaments and so forth (where the latter in turn underpin the development of new institutions):

"Institutions are not only themselves the result of a selective and adaptive process which shapes the prevailing or dominant types of spiritual attitude and aptitudes; they are at the same time special methods of life and of human relations, and are therefore in their turn efficient factors of selection. So that the changing institutions in their turn make for a further selection of individuals endowed with the fittest temperament, and a further adaptation of individual temperament and habits to the changing environment through the formation of new institutions" (ibid, p. 188). 
With social structure regarded as ideational Veblen appears to hint at a somewhat reductionist stance, at least in principle if not in practice, in appearing to suggest that social structure is ultimately reducible to biological and physicalist factors:

"The forces which have shaped the development of human life and of social structure are no doubt ultimately reducible to terms of living tissue and material environment; but proximately for the purpose in hand, these forces may best be stated in terms of an environment, partly human, partly non-human, and a human subject with a more or less definite physical and intellectual constitution" (ibid, p. 189).

If institutions are prevalent and so shared habits of thought does this mean that human nature is reasonably common across individuals, or groups of individuals, at any point in time (even if not fixed over time)? Presumably at this earlier point in his intellectual development Veblen thought not. For, if there is to be (natural) selection of types ("of individuals endowed with the fittest temperament") by or through prevalent institutions, then variation in types is seemingly required. According to Veblen, in fact, the human subject is more or less variable, but that at any point in time it is the case that one persistent and relatively stable type of body and of temperament rises into dominance (and thereafter serves to further elaborate institutions handed down from the past);

"Taken in the aggregate or average, this human subject is more or less variable; chiefly, no doubt, under a rule of selective conservation of favorable variations. The selection of favorable variations is perhaps in great measure a selective conservation of ethnic types. In the life history of any community whose population is made up of a mixture of divers ethnic elements, one or another of several persistent and relatively stable types of body and of temperament rises into dominance at any given point. The situation, including the institutions in force at any given time, will favor the survival and dominance of one type of character in preference to another; and the type of man so selected to continue and to further elaborate the institutions handed down from the past will in some considerable measure shape these institutions in his own likeness" (ibid, p. 189).

Whilst there is thus a selection process in play between the different relative stable types of character, within any given stable type of character, at a point in time, there is also a simultaneous process of selection of specific habits of thought:

"But apart from selection as between relatively stable types of character and habits of mind, there is no doubt simultaneously going on a process of selective adaptation of habits of thought within the general range of aptitudes which is characteristic of the dominant ethnic type or types. There may be a variation in the fundamental character of any population by selection between relatively stable types; but there is also a variation due to adaptation in detail within the range of the type, and to selection between specific habitual views regarding any given social relation or group of relations" (ibid, p. 189-90).

However, whichever is the case, or 'by one method or another', institutions change and develop; and this institutional change constitutes the change of society:

"Institutions must change with changing circumstances, since they are of the nature of an habitual method of responding to the stimuli which these changing circumstances afford. The development of these institutions is the development of society. The institutions are, in substance, prevalent habits of thought with respect to particular relations and particular 
functions of the individual and of the community; and the scheme of life, which is made up of the aggregate of institutions in force at a given time or at a given point in the development of any society, may, on the psychological side, be broadly characterized as a prevalent spiritual attitude or a prevalent theory of life. As regards its generic features, this spiritual attitude or theory of life is in the last analysis reducible to terms of a prevalent type of character" (ibid, p. 190).

So how does it all work? Clearly as with any natural selection story, the totality of the components or processes in question, here social ones, put in an appearance of order if they put in any appearance at all. Veblen provides the details. In effect the natural selection mechanism works to ensure that the conditions of the past always shape, and indeed are manifest in, the situation of the present. Prevailing conditions at any point in time provide an environment of selection on (the population of actual or potential) habits of thought, by discouraging some and reinforcing others. Habits which thereby become settled are carried over to a future in which they will typically turn out to be less than fully adequate, but may nevertheless remain consequential:

"The situation of today shapes the institutions of tomorrow through a selective, coercive process, by acting upon men's habitual view of things, and so altering or fortifying a point of view or a mental attitude banded down from the past. The institutions -- that is to say the habits of thought -- under the guidance of which men live are in this way received from an earlier time; more or less remotely earlier, but in any event they have been elaborated in and received from the past. Institutions are products of the past process, are adapted to past circumstances, and are therefore never in full accord with the requirements of the present" (ibid, p. 190-1).

Of course, it is the case that as contextual circumstances change, pre-existing institutions are rendered less than in full accord with the requirements of the emergent situation; and this in turn prompts adaptation, and so on for ever:

"In the nature of the case, this process of selective adaptation can never catch up with the progressively changing situation in which the community finds itself at any given time; for the environment, the situation, the exigencies of life which enforce the adaptation and exercise the selection, change from day to day; and each successive situation of the community in its turn tends to obsolescence as soon as it has been established. When a step in the development has been taken, this step itself constitutes a change of situation which requires a new adaptation; it becomes the point of departure for a new step in the adjustment, and so on interminably.

It is to be noted then, although it may be a tedious truism, that the institutions of today -- the present accepted scheme of life -- do not entirely fit the situation of today. At the same time, men's present habits of thought tend to persist indefinitely, except as circumstances enforce a change. These institutions which have thus been handed down, these habits of thought, points of view, mental attitudes and aptitudes, or what not, are therefore themselves a conservative factor. This is the factor of social inertia, psychological inertia, conservatism" (ibid, p. 191).

This latter passage and others suggest that, in the Leisure Class at least, institutions are regarded by Veblen as relatively static. If the focus of the institutionalist tradition has been more upon this earlier orientation of Veblen this likely goes some way to explaining the acceptance of the (earlier noted) 'Veblen Dichotomy' amongst some of its members. 
It is presumably just because human nature is considered to be the source of consistency and stability in the later Marginal Utility essay, whereas the latter is variable in the earlier text, that a presumption of relatively static institutions is required in the earlier work to explain the occurrence of any stability and consistency in social life at all.

Nevertheless in the earlier text too Veblen recognises that institutions do change. And societal evolution consists in a process whereby individuals revise their habits of thought when the latter no longer suit the material situation. With social structure purely ideational or mentalistic if follows that the evolution of society is essentially a 'process of mental adaptation':

"Social structure changes, develops, adapts itself to an altered situation, only through a change in the habits of thought of the several classes of the community, or in the last analysis, through a change in the habits of thought of the individuals which make up the community. The evolution of society is substantially a process of mental adaptation on the part of individuals under the stress of circumstances which will no longer tolerate habits of thought formed under and conforming to a different set of circumstances in the past" (ibid, p. 192).

Interestingly, Veblen adds that

"For the immediate purpose it need not be a question of serious importance whether this adaptive process is a process of selection and survival of persistent ethnic types or a process of individual adaptation and an inheritance of acquired traits" (ibid, p. 192).

This passage is interesting because Veblen is often interpreted as Darwinian in his thinking, whereas the notion of 'an inheritance of acquired traits' is associated more with Lamarck than with Darwin.

If we add to the various factors identified a recognition that at this time a community can be understood as an industrial or economic mechanism, then Veblen's preconception of social order, at least at the time of writing the Leisure Class, is perhaps usefully conveyed in the following passage:

"Any community may be viewed as an industrial or economic mechanism, the structure of which is made up of what is called its economic institutions. These institutions are habitual methods of carrying on the life process of the community in contact with the material environment in which it lives. When given methods of unfolding human activity in this given environment have been elaborated in this way, the life of the community will express itself with some facility in these habitual directions. The community will make use of the forces of the environment for the purposes of its life according to methods learned in the past and embodied in these institutions." (ibid, pp. 193-4).

When, however, this 'given environment' changes, existing institutions prove less appropriate to it and somehow must adapt:

"If the scheme according to which the life process of the group was carried on under the earlier conditions gave approximately the highest attainable result -- under the circumstances -- in the way of efficiency or facility of the life process of the group; then 
the same scheme of life unaltered will not yield the highest result attainable in this respect under the altered conditions" (ibid, p. 194).

With the focus at this stage more on natural selection than habituation, Veblen seemingly feels less need to describe the process other than through variation and selection (albeit notably of the 'fittest', or of the 'approximately [...] highest attainable result'). He is clear, however, that adaptations in institutions brought about by environmental change will inevitably impact differentially across the population. "In the redistribution of the conditions of life that comes of the altered method of dealing with the environment, the outcome is not an equable change in the facility of life throughout the group" (ibid, p. 194-5).

\section{Accounting for Veblen's changed conception of order}

There is clearly a significant explanatory puzzle to be resolved in all this in that the account of order that is present in the Leisure Class is, though similar in its components and various background preconceptions to the later Marginal Utility essay, also remarkably different in various aspects. In the latter essay, all referencing of natural selection has disappeared as Veblen seemingly prefers instead to give centrality to, and put significant analytical reliance upon, processes of habituation. Also in the later work there is little talk of developments of, or of selection amongst, traits of human nature, ethnic types, or types of character generally, whereas the account of the Leisure Class, at times, amounts more or less to a form of biological reductionism. And whereas in the earlier text Veblen seems to accept the inevitability, certainly the concept, of social progress this seems to be absent from his later thinking.

On the presumption that the suggested account of differences is correct, the likely explanation I suggest, is that Veblen, in the earlier period at least, was significantly influenced by the evolutionary writings of not merely Darwin but also, and perhaps especially, Herbert Spencer; and that it was only after his writing of relevant sections of the Leisure Class that Veblen's evolutionary theorising became more consistent with that of Darwin.

There are several reasons for interpreting the earlier text as one likely written more under the influence of Spencer than Darwin. First, the only feature that is basic to Darwin is that of processes of causation, whereby each phenomenon is 'descendant' from aspects of what was there before. Although Darwin certainly introduced the term 'natural selection' he insisted that it represented one causal process amongst others (see Lawson, 2003a, especially p. 112). It was Spencer, who coined the phrase 'survival of the fittest' to capture the process of natural selection, and who most lauded this mechanism. Although Veblen likely wished not to use the term 'fittest' in quite so laudatory a manner as Spencer, he does, as we have seen, write in terms of "natural selection of the fittest habits of thought", "the fittest temperament", "approximately the highest attainable result", and so on, seemingly aware of the connotations that terms like 'fittest' and 'highest' inevitably carry.

Second, Spencer is easy to interpret as something of a biological reductionist, whereby his theory of natural selection entails that social explanations reduce to individual and then to biological terms ${ }^{21}$. Although this typically is not how commentators characterise Veblen, there is a suggestion of this position in Veblen's remarks in the Leisure Class, as we have seen.

\footnotetext{
${ }^{21}$ And is so within old institutionalism. See Hodgson, 1998, p. 416
} 
Third, as we have also seen, Veblen allows the possibility of the inheritance of acquired traits. Although Darwin was not entirely opposed to this notion, it is an idea basically stemming from Lamarck with whom Spencer strongly associated ${ }^{22}$. Related to this, and perhaps most significant of all, is Veblen's apparent acceptance of the idea that evolution typically brings progress, including by way of inheritance of acquired characteristics. This again is an especially Spencerian emphasis. Spencer, in fact, developed an all-encompassing theory of evolution as the progressive development of the physical world, biological organisms, the human mind, human culture and societies. More specifically, Spencer $(1857)^{23}$ proposed an evolutionary theory whereby everything in the universe develops from a simple, undifferentiated, homogeneity to a complex, differentiated, heterogeneity, while being accompanied by a process of greater integration of the differentiated parts. This theory notably constitutes an attempt to explain the evolution of complexity. For Spencer the primary mechanism of species transformation is Lamarckian use-inheritance according to which organs are either developed through use or diminished through disuse and that the resulting changes may be transmitted to future generations. Spencer argues that this evolutionary mechanism can also explain 'higher' evolution, especially the social development of humanity. In all this, that which evolves adapts to its situation.

This sort of conception seems significantly to inform Veblen's account as found in the Leisure Class, even though Veblen presents his own theories more cautiously and subtly. Consider the following passage:

"Social advance, especially as seen from the point of view of economic theory, consists in a continued progressive approach to an approximately exact "adjustment of inner relations to outer relations", but this adjustment is never definitively established, since the "outer relations" are subject to constant change as a consequence of the progressive change going on in the "inner relations." But the degree of approximation may be greater or less, depending on the facility with which an adjustment is made. A readjustment of men's habits of thought to conform with the exigencies of an altered situation is in any case made only tardily and reluctantly, and only under the coercion exercised by a stipulation which has made the accredited views untenable. The readjustment of institutions and habitual views to an altered environment is made in response to pressure from without; it is of the nature of a response to stimulus" (Veblen 1899a [1998], p. 192)

Although Veblen puts his references to inner and outer relations in quotation marks, indicating that it is someone else's phraseology, Veblen does not indicate the source, thereby suggesting perhaps that it is someone so obvious and familiar to him that no explicit identification is required. As it happens, the only contributor of whom I am aware who regularly, in evolutionary contexts, employs this terminology of the "adjustment of inner relations to outer relations" is Spencer. In fact Spencer repeatedly does so to express his thesis that phenomena more or less everywhere adapt in such a manner as to come to correspond to the nature of their specific environments. For example:

\footnotetext{
${ }^{22}$ Indeed, in his second book, entitled Principles of Psychology, Spencer (1855) explores a physiological basis for psychology, maintaining that the workings of the human mind are law-like and discoverable within the framework of general biology. This was interpreted to allow a developmental perspective not merely in terms of the individual (as in traditional psychology), but also of the species and the race. Spencer argues here (building in turn on Mill) that repeated associations of ideas are embodied in the formation of specific strands of brain tissue, and these could be passed from one generation to the next by means of the Lamarckian mechanism of use-inheritance. Veblen seems to be allowing something similar.

${ }^{23}$ In his essay, 'Progress: Its Law and Cause', published in Chapman's Westminster Review in 1857, and which later formed the basis of the First Principles of a New System of Philosophy (1862).
} 
"Thus then we find variously illustrated in detail, the truth enunciated at the outset, that all vital phenomena are directly or indirectly in correspondence with phenomena in the environment. Whether the kind of Life contemplated be that embraced by Physiology, or that of which Psychology treats, it equally consists of internal changes that mediately or immediately conform to external coexistences and sequences. The assimilative processes going on in a plant, and the reasonings by which a man of science makes a discovery, alike exhibit the adjustment of inner relations to outer relations" (Spencer 1855, chapter XV, $\S 165$-- emphasis added by TL).

This process also applies to all life forms:

"Thus, it will be manifest, that from the lowest to the highest forms of life, the increasing adjustment of inner to outer relations, is, if rightly understood, one indivisible progression” (Spencer 1855, chapter XV, §165 -- emphasis added by TL).

and also to intelligence:

"Every form of Intelligence being, in essence, an adjustment of inner to outer relations; it results that as, in the advance of this adjustment, the outer relations increase in number, in complexity, in heterogeneity, by degrees that cannot be marked; there can be no valid demarcations between the successive phases of Intelligence" (Spencer 1855, chapter XV, $\S 166$-- emphasis added by TL).

Veblen, as I say, is more subtle, allowing that the sort of adjustment under discussion "is never definitively established, since the 'outer relations' are subject to constant change as a consequence of the progressive change going on in the 'inner relations.'. But the influence of Spencer on Veblen in this seems evident. As I say the additional fact of quotation marks without explicit reference seems also to suggest a familiarity that is recognised ${ }^{24}$.

In any case, accepting this perspective, but allowing that the environment can change, then social progress, and indeed 'freedom', according to Veblen, is bound up with exposure to environmental pressures to change:

"Freedom and facility of readjustment, that is to say capacity for growth in social structure, therefore depends in great measure on the degree of freedom with which the situation at any given time acts on the individual members of the community - the degree of exposure of the individual members to the constraining forces of the environment. If any portion or class of society is sheltered from the action of the environment in any essential respect, that portion of the community, or that class, will adapt its views and its scheme of life more tardily to the altered general situation; it will in so far tend to retard the process of social transformation." (Veblen (1899a [1998], p. 193)

\footnotetext{
${ }^{24}$ Perhaps it was. According to Dorfman (1934, p. 30) Veblen is known to have read Spencer in the 1870s when he was a student at Carleton College; and to have come under the influence of William Graham Sumner, a prominent advocate of Spencerian evolutionary principles in the social sciences, when at Yale in the 1880s (Dorfman, 1934, pp. 43-6; Riesman, 1963, p. 19). Like many others, Veblen spent a good deal of time studying Spencer's and Sumner's ideas of socio-economic evolution (Edgell, 1975; Edgell and Tilman, 1989; Eff, 1989; Murphree, 1959; Hodgson, 1998).
} 
It is because the leisure classes on whom Veblen focuses are relatively protected, of course, that they are relatively slow to evolve, and when they do the causes are usually economic circumstances.

"The wealthy leisure class is in such a sheltered position with respect to the economic forces that make for change and readjustment. And it may be said that the forces which make for a readjustment of institutions, especially in the case of a modern industrial community, are, in the last analysis, almost entirely of an economic nature." (ibid, p. 193)

\section{Veblen's evolutionary essay}

If the philosophical emphasis of the Leisure Class can be put down to the influence of Spencer, it presumably follows that this influence bore upon other contributions written at the time. Of interest here is that, in the set of papers published at the end of the nineteenth century (Veblen, 1898, 1899b, 1899c, 1900), papers in which Veblen questions why economics is not yet an evolutionary science, Veblen does distinguish evolutionary science as modern, but is interpreted by various commentators as suggesting not that an evolutionary science is better or more laudatory than others, but merely that it is coming about (see for example Helge Peukert, 2001, or Warren Samuels, 1990, 1998).

Elsewhere I have suggested that this assessment is not quite right (Lawson, 2002; 2003a, chapter 8). Certainly Veblen does not advance a conception of evolutionary science as a constructive programme. But this is because he believes that there is little reason for him to do so, anticipating that economics was becoming an evolutionary science anyway ${ }^{25}$. In particular, Veblen thought it was becoming dominant via a process of natural selection. In this he is at pains to avoid implying that his anticipation that economics would become an evolutionary science is at all connected with any judgements he himself might make regarding the worth of the evolutionary method. That is, he was keen to apply the evolutionary method, as he understood it, in a consistent manner, to be an early evolutionary epistemologist. But Veblen does make comparative appraisals. He does favour (and, at least in footnotes, defend) the evolutionary method or its preconditions. Veblen does believe in scientific progress. This assessment made elsewhere is backed up by consideration of the Leisure Class, and seemingly bears the implication that, even in his methodological essays, Veblen was as much influenced by Spencer as by Darwin.

\section{$X$ The explanatory puzzle (of a changing conception of order) transformed}

If the immediate explanation of Veblen's changed conception of social order between writing the Leisure Class book and the Marginal Utility essay is that he increasing abandoned various Spencerian notions that influenced the writing of his former text, there remains a question of why he did. In particular, why did Veblen abandon the emphasis on progress?

In the Leisure Class, the impression is imparted that human nature progresses through natural selection and this in turn underpins supposed progress in the otherwise relatively static habits of

\footnotetext{
${ }^{25}$ In this of course Veblen has proven to be mistaken. Indeed as Anne Mayhew (1998) observes "even as Veblen issued his call for an evolutionary economics - a call to contribute to a grand structure that seemed to be on the verge of creation - the evolutionary vision in the social sciences had begun to fade" (p. 452). Anthropology, in particular, the discipline with Which Veblen's evolutionary account arguably shared the most (Mayhew 1998), became a discipline devoted to the local and the present. I cannot explore here the many factors explaining this generalised pattern here, but see discussions in for example Leaf 1979; Lowie 1937; Eggan 1968; and especially Stocking 1968 or Mayhew 1998.
} 
thought, which in turn impact back on the selection of human traits. Yet by the time of the Marginal Utility essay, the habits of thought or institutions are certainly said to change fairly continuously, whilst in contrast "the underlying traits of human nature (propensities, aptitudes, and what not) [....] remain substantially unchanged", (and indeed they in turn impart a relative stability also to social structure). Why then does Veblen eventually abandon the earlier emphasis?

The explanation, I suggest, is that in the period between the two texts Veblen became familiar with the work of Gregor Johann Mendel, an Austrian monk and botanist, who, experimenting with peas, had earlier published results that suggested that acquired traits are not passed on, and that genetic inheritance takes place according to certain unchanging laws. These laws (which became known as Mendel's laws of genetic inheritance) support the view that species remain unchanged. Mendel's work is certainly open to the interpretation that developed traits of human beings cannot be passed on through reproduction. With the conception of human nature seemingly rendered thereby more stable than Veblen had originally allowed, social structure including institutions could analytically be allowed to be more variable.

In fact Mendel had published his findings as early as 1865 and 1866. But they were originally largely overlooked, and became widely recognised only following their 'rediscovery' in 1900 by three European scientists, Hugo de Vries, Carl Correns, and Erich von Tschermak. From that point onwards, however, they were enthusiastically embraced by various evolutionists, not least of by William Bateson working at Cambridge (UK) University, who coined the terms "genetics" and "allele" to describe fundamental features of the theory. Between 1900 and 1910 Bateson directed a rather informal "school" of genetics at Cambridge, and it is not inconceivable that Veblen kept abreast of some of these and/or related research activities ${ }^{26}$.

Support for this explanation of Veblen's changing conception of social order can be obtained from Veblen's wider writings that do reveal an eventual awareness of Mendel's findings, an awareness that came after his writing the Leisure Class

\section{Additional Sources}

Perhaps the clearest indication that it is Mendel's results that influenced the noted change in Veblen's thinking is found in a passage in a collection of Veblen's essays posthumously published under the head of Essays in our Changing Order; and which I will abbreviate to the Order Collection.

It is in fact in the very first of the essays in the Order Collection, titled Economic Theory in the Calculable Future, and originally published in 1925, that the passage is found, revealing that by the time of its publication at least, Veblen is certainly abreast of 'Mendelian' findings.

Here Veblen observes that at the turn of the twentieth century researchers ('the Victorians' presumably including himself, though he seemingly craftily points the finger instead at Nassau Senior) had looked to find stability in institutions and to find change in human nature. However, the 'current generation' are 'inhibited' from finding change in the human factor,

\footnotetext{
${ }^{26}$ Interestingly, Bateson's group consisted mostly of women associated with Newnham College, Cambridge, who assisted in this research programme at a time when Mendelism was only just becoming a legitimate field of study. Between 1902 and 1910 they carried out a series of breeding experiments using various plant and animal species, obtaining results that both supported and extended Mendel's laws of heredity.
} 
writes Veblen, because "the Medelians forbid it", so the question is not what explains a 'static state' of social structure but to account for growth and change:

"These principles of common sense and common information prevalent in this opening quarter of the century are of an evolutionary, or genetic complexion, in that they hold the attention to the changes that are going forward, rather than focus it on that "Natural State of Man," as Nassua Senior called it, to which the movement of history was believed inevitably to tend. The question now before the body of economists is not how things stabilize themselves in a "static state," but how they endlessly grow and change. But in its purview of this genetic proliferation of phases current knowledge and belief see growth and change only in that field in which the Victorians looked to see an indefeasible stability - the field of human institutions, use and wont, law and custom, the state of the industrial arts; whereas this current generation is inhibited from looking for substantial change where the Victorians found their comfort in recognizing it, - in the human factor. There is for them no "perfectibility of the human race," whether through education or through breeding; the Mendelians forbid it, and in practical effect they are allowed to have the right of it. Tempora mutantur sed nos non mutamur in illis" [times are changing but we do not change with them $-\mathrm{TL}^{27}$ ] (Veblen, 1925, p. 51).

This passage is clearly significant. But actually, a study of the The Instinct of Workmanship reveals that ten years or so earlier, in 1914, Veblen had already assimilated the Mendelian rediscoveries. Veblen's focus in the early part of the latter study is very much on human nature and specifically human instinct, or more properly "the complement of instinctive proclivities and tropismatic aptitudes" (Veblen, 1914, p. 1). The instincts, in particular, are viewed as the prime movers in all behaviour, both initiating, and setting limits to conduct ${ }^{28}$.

Noting that these terms are increasingly being discarded in other disciplines Veblen is of the view that to meet the "needs of an inquiry into the nature and causes of the growth of institutions" it will be necessary to take account of the conditioning role of "the innate and persistent propensities of human nature; and for these propensities, as they take effect in the give and take of cultural growth, no better designation than the time-worn "instinct" is available" (ibid pp. 2-3).

Basically, for Veblen tropismatic elements are simple and irreducible psychological elements of human behaviour that "fall into composite functional groups, and so make up specific and determinate propensities, proclivities, aptitudes that are, within the purview of the social sciences, to be handled as irreducible traits of human nature." In turn, these various proclivities are classed together as "instincts", where the latter are intrinsically teleological or goal or 'objective end' oriented ${ }^{29}$.

\footnotetext{
${ }^{27}$ Although many contributors had previously written on the 'perfectability of the human race' I note that one of them was Spencer.

${ }^{28}$ According to Veblen: "Not only is the continued life of the race dependent on the adequacy of its instinctive proclivities in this way, but the routine and details of its life are also, in the last resort, determined by these instincts. These are the prime movers in human behaviour, as in the behaviour of all those animals that show self-direction or discretion. Human activity, in so far as it can be spoken of as conduct, can never exceed the scope of these instinctive dispositions, by initiative of which man takes action. Nothing falls within the human scheme of things desirable to be done except what answers to these native proclivities of man. These native proclivities alone make anything worthwhile, and out of their working emerge not only the purpose and efficiency of life, but its substantial pleasures and pains as well" (ibid p.1).

${ }^{29}$ Veblen writes: "These various native proclivities that are so classed together as "instincts" have the characteristic in common that they all and several, more or less imperatively, propose an objective end of endeavour. On the other hand what distinguishes one instinct from another is that each sets up a characteristic purpose, aim, or object to be attained, different from the objective end of any other instinct. Instinctive action is teleological, consciously so, and the teleological scope and
} 
Veblen has a good deal to say on all this, most of which I cannot enter into here. The feature that I do want to draw out, however, is how human nature is interpreted in the light of an acknowledged Mendelian perspective. Although instincts are regarded as hereditary traits, Veblen seemingly no longer feels able to talk of the inheritance of acquired characteristics.

Even so, variety can nevertheless occur not only through 'Mendelian mutation' (ibid, p. 16), but also though recombination of other more basic units. Because the instincts are not regarded as basic psychological units but are comprised out of the latter, the different ways in which the basic psychological units can be combined gives rise to variety or 'individuality among the members of the race'. Thus Veblen discusses at length how Mendel's contribution still allows the possibility of a good deal of variation (ibid, p. 14).

After all things are considered, however, Veblen ends cautioning that, for Mendelian reasons, such variety must ultimately be limited, that scope for adapting our instinctive natures to different circumstances is relatively little, certainly compared to the scope of adaptability of institutions:

"But after all has been said it remains true that the margin within which the instinctive nature of the race can be effectively adapted to changing circumstances is relatively narrow - narrow as contrasted with the range of variation in institutions - and the limits of such adaptation are somewhat rigid." (ibid pp. 35-6)

\section{Final Comments and Conclusions}

Throughout his writings Veblen's conception of social order rests upon the following components: human nature, human conduct, habits of thought, habits of conduct, and the remaining material environment.

Human nature includes capacities and proclivities, not least the ability of human beings to habituate. In Veblen's early writings traits of human nature are thought to evolve, and indeed progress, through processes of natural selection. In his later writings, seemingly after taking on board Mendelian writings and findings, Veblen regards human nature as rather more fixed.

Habits of thought, when they are widespread and enduring (or prevalent and settled), constitute Veblen's notion of institutions, with the two terms, in the earlier writings at least, often used interchangeably. These habits of thought essentially relate to principles of conduct, these being contextually situated and always liable to change. They constitute strategies and the like for interacting/relating to others. When theses habits of thought are so settled and prevalent they comprise the elements of culture, basically understood as a community's scheme of life.

Social life is ordered by shared (ideational) schemes that constitute the cultural, including institutional, fabric. Such ideational schemes govern conduct including habitual conduct, and are 'simultaneously' reproduced through it.

aim of each instinctive propensity differs characteristically from all the rest. The several instincts are teleological categories, and are, in colloquial usage, distinguished and classed on the ground of their teleological content." (ibid p.3) 
An impetus to social change can originate in any quarter, but most especially by way of changes to uncontrollable factors in the background material environment, not least changes in technology or methods of dealing with the materiality of life. These changes impact on human conduct, whereby through processes of habituation, various signals and stimuli come to be responded to more or less automatically, and new or transformed habits (of conduct) develop. Where these become established and widespread, they give rise to settled habits of thought or institutions. Thereafter they can in turn be used to guide conduct in areas in, and for, which they were not originally developed. In this way, for example, business habits of thought become seemingly all prevalent.

Throughout Veblen' contributions the process whereby order develops and changes is described as evolutionary and couched thereby in terms of cumulative causation. In the early period this process appears to be one in which the natural selection mechanism is ubiquitous, and progress is characteristic, couched in terms both of underlying traits of human nature and of habits of thought. By the later period, the emphasis on natural selection is reduced, human traits are regarded as less variable, and social change is couched less in terms of progress and much more in terms of unfolding process.

All such social orders are associated with a degree of stability allowing them to be recognised as such, and as a condition of human co-ordination. In the earlier period Veblen seems to attribute this stability mostly to tardy habits of thought, thereby likely encouraging the interpretation that came to be formalised as the insitutionalist notion of a Veblenian dichotomy (technology is change; institutions constitute fixity). With time, however, and specifically once the findings of Mendel are taken on board, the stability is imputed instead to traits of human nature that underpin the process of habituation and thus ensure that all social change involves elements of significant continuity and stability.

Although I have attempted to give a reasonably comprehensive overview of issues central to my topic, the current essay inevitably remains in various ways but a partial account of Veblen's overall development; numerous relevant issues less directly related to my theme have had to be omitted. One final notable observation that I might briefly also mention before finishing is that, at least with regard to the Order Collection whose chapters span a lengthy period, Veblen, with the passage of time, appears to mention the term 'institution' less and less frequently. Instead he contents himself merely with making reference to habits of thought. Or more precisely, and perhaps in order to reduce the possibility of his ideas being misinterpreted by others, Veblen writes increasingly only in terms both of principles of conduct (including especially habits of thought) and actual practical conduct (including especially habits of conduct).

An interesting example in this regard is Veblen's Bolshevism is a Menace - to Whom?, originally published in 1919. Although the focus of this piece clearly is, to use my own term, social transformation, Veblen writes exclusively in terms of habits of thought and an ideational order, and never once mentions the term institution. Specifically:

"It is always as a system of ideas, or 'principles,' that Bolshevism spreads by communication; it is a contamination of ideas, of habits of thought. And it owes much of its insidious success to the fact that this new order of ideas which it proposes is extremely 
simple and is in the main of a negative character. The Bolshevist scheme of ideas comes easy to the common man because it does not require him to learn much that is new $[\ldots]^{30}$.

In particular Veblen is of the view that the situation, training and daily life of ordinary people -- or of the 'common man' -- does not induce an attachment to 'mental attitudes' accepting of rights of ownership, class privilege and so forth, none anyway that are not easily changed if challenged $^{31}$. So the habits of thought of the 'common man' are easily adjusted to ways of thinking in line with Bolshevik principles. The same, though, cannot be said of the mental attitudes of those directly involved and benefiting from what Veblen calls the 'business traffic'. These business interests are not especially those of the common man, and so have little bearing on 'his' habitual outlook ${ }^{32}$.

Veblen's answer, then, to the question posed in the title of the paper (Bolshevism is a Menace - to Whom?) is that it is a menace not to the common man but only to the business community $^{33}$. The point here, though, is that, despite Veblen's talk of the 'order of things' and of factors that change it being couched in terms of property rights, ownership, business, privilege and the rest of it, all of the action is couched in terms of habits of thought. A transformational in social structure seemingly turns on only slight adjustments to ways of thinking. With the primary focus so clearly upon mental processes references to terms like institution, as noted, no longer make an appearance at all.

Still that is perhaps just an aside, though indicative of the necessary incompleteness of the picture so far conveyed on even the specific focus of this paper.

If the assessment of the current paper as a whole is broadly correct the main consequences of the findings, other than reinforcing recognition that Veblen is a truly important contributor to the discipline, bear, I suspect, and as already noted, on various assessments maintained within

${ }^{30}$ More expansively Veblen writes:

"It is always as a system of ideas, or 'principles', that Bolshevism spreads by communication; it is a contamination of ideas, of habits of thought. And it owes much of its insidious success to the fact that this new order of ideas which it proposes is extremely simple and is in the main of a negative character. The Bolshevist scheme of ideas comes easy to the common man because it does not require him to learn much that is new, but mainly to unlearn much that is old. It does not propose the adoption of a new range of preconceptions, so that it calls for little in the way of acquiring new habits of thought. In the main it is an emancipation from older preconceptions, older habitual convictions. And the proposed new order of ideas will displace the older preconceptions all the more easily because these older habitual convictions that are due to be displaced, no longer have the support of those material circumstances which now condition the life of the common man, and which will therefore make the outcome by bending his habits of thought." (Veblen, 1919, pp. 404-5).

31 "The training given by the mechanical industries and strengthened by the experience of daily life in a mechanically organized community lends no support to prescriptive rights of ownership, class perquisites, and free income. This training bends the mental attitude of the common man at cross-purposes with the established system of rights, and makes it easy for him to deny their validity so soon as there is sufficient provocation. And it is scarcely necessary for him to find a substitute for these principles of vested right that so fall away from him." (ibid, p. 405).

32 "It is true, these prescriptive rights, about whose maintenance and repair the whole quarrel swings and centers, do have the consistent support of those habits of thought that are engendered by experience in business traffic; and business traffic is a very large and consequential part of life as it runs in these civilized countries. But business traffic is not the tone-giving factor in the life of the common man, nor are business interests his interests in so obvious a fashion as greatly to affect his habitual outlook. Under the new order of things there is, in effect, a widening gulf fixed between the business traffic and those industrial occupations that shape the habits of thought of the common man." (ibid, pp. 405-6).

33 Veblen writes:

"The business community, who are engaged in this business traffic and whose habitual attention centers on the rights of ownership and income, are consistent votaries of the old order, as their training and interest would dictate. And these are also immune against any subversive propaganda, however insidious, as has already been remarked above. Indeed, it is out of this division of classes in respect of their habitual outlook and of their material interests that the whole difficulty arises, and it is by force of this division that this subversive propaganda becomes a menace. [......]

By first intention and by consistent aim Bolshevism is a menace to the vested rights of property and of privilege, and from this the rest follows." (ibid, p. 406). 
that strand of the institutionalist tradition that most associates itself with Veblen. Here, various proponents, drawing especially on insights from modern theorising in social ontology regarding social emergence, the causal and ontological irreducibility of aspects of social reality (see Lawson 2013a, 2013b), not all of which is ideational, have affected to find them all these features in Veblen and thereby regarded them as quintessentially institutional. It is thus perhaps a challenge to this group of thinkers to reconcile such claims with the sorts of findings reported here that social structure for Veblen is ideational in nature, comprising most essentially habits of thought, with the category of institution itself (as opposed to habits of thought per se) seemingly being increasingly deemphasised over time.

I suspect, in fact, that Veblen would be a little surprised by much that has come to pass that bears specifically on his output and projections. The list of surprises would surely include the widespread use of his category of neoclassical as it is found in economics today (see Lawson, 2013c), as well as the continuing dominance of taxonomic economic science and the associated failure of economic science to become evolutionary. It might also include the demise of Bolshevism. But so too it would likely also cover some of the conceptions, methods, assertions and interpretations (not least of the categories habit, habituation and institution) that have become systematised explicitly as Veblenian.

\section{References}

Ayres, Clarence E. (1944) The Theory of Economic Progress, 1st ed. Chapel Hill, N.C.: University of North Carolina Press, 1944.

Bush, Paul Dale (1987) “Theory of Institutional Change.” Journal of Economic Issues 21 (September): 1075-1116.

Bush, Paul Dale (1989) "The Concept of Progressive Institutional Change and the Implications for Economic Policy Formation.” Journal of Economic Issues 23 (June): 445-64.

Dorfman, J. 1934. Thorstein Veblen and His America, New York, Viking Press. Reprinted (1961), New York, Augustus Kelley

Dugger, William M. (1995) "Veblenian Institutionalism: The Changing Concepts of Inquiry." Journal of Economic Issues 39, no. 4 (December): 1013-1027.

Edgell, S. 1975. Thorstein Veblen's theory of evolutionary change, American Journal of Economics and Sociology, vol. 34, July, 267-80

Edgell, S. and Tilman, R.1989. The intellectual ancedents of Thorstein Veblen: a reappraisal, Journal of Economic Issues, vol. 23, no. 4, December, 1003-26

Eff, E. Anton, (1989) 'History of thought as ceremonial genealogy: the neglected influence of Herbert Spencer on Thorstein Veblen', Journal of Economic Issues, vol. 23, no. 3, September, 689-716.

Eggan, F. 1968. One hundred years of ethnology and social anthropology, in Brew, J. O. (ed.), One Hundred Years of Anthropology, Cambridge, MA, Harvard University Press

Hamilton, David (1991) Evolutionary Economics: A Study of Change in Economic Thought. 1953. Reprint, New Brunswick, N.J.: Transaction Publishers, 1991.

Hodgson, Geoffrey, M (1998) 'On the evolution of Thorstein Veblen's evolutionary economics', Cambridge Journal of Economics, 22: 415-431

Hodgson, Geoffrey, M (2002) Economics and Utopia: Why the Learning Economy is Not the End of History, London and New York: Routledge.

Hodgson, Geoffrey, M (2004) 'Reclaiming habit for institutional economics', Journal of Economic Psychology, 25: 651-660 
Hodgson, Geoffrey, M (2006) 'What are institutions?' Journal of Economic Issues, Vol. XL No. 1 March.

Klein, Philip A., and Edythe S. Miller (1996) "Concepts of Value, Efficiency, and Democracy in Institutional Economics.” Journal of Economic Issues 30, no.1 (March): 267-77.

Knoedler, Janet, and Anne Mayhew (1999) 'Thorstein Veblen and the Engineers: A Reinterpretation', History of Political Economy 31:2

Leaf, M. 1979. Man, Mind, and Science: A History of Anthropology, New York: Columbia University Press.

Lawson, Tony (2002) 'Should Economics Be an Evolutionary Science? Veblen's Concern and Philosophical Legacy' (the Clarence Ayres Memorial Lecture), Journal of Economic Issues, 6(2):279-92.

Lawson, Tony (2003a) Reorienting Economics, London and New York: Routledge.

Lawson, Tony (2003b) 'Institutionalism: On the Need to Firm up Notions of Social Structure and the Human Subject', Journal of Economic Issues, XXXVII (1):175-207, March.

Lawson, Tony (2004[2015]) 'What is an Institution?' memo: Cambridge. Forthcoming in in Stephen Pratten (ed.) (2015) Social Ontology and Modern Economics, London and New York: Routledge

Lawson, Tony (2012a) 'Ontology and the Study of Social Reality: Emergence, Organisation, Community, Power, Social Relations, Corporations, Artefacts and Money', Cambridge Journal of Economics, 36(2):345-85.

Lawson, Tony (2012b) 'Mathematical Modelling and Ideology in the Economics Academy: competing explanations of the failings of the modern discipline?', Economic Thought, (1):3-22.

Lawson, Tony (2013a) 'Emergence and Social Causation' in John Greco and Ruth Groff (eds.), Powers and Capacities in Philosophy, London and New York: Routledge, pp285308.

Lawson, Tony (2013b) 'Emergence, Morphogenesis, Causal Reduction and Downward Causation', in Margaret Archer (ed.), Social Morphogenesis, New York: Springer, pp. 6184.

Lawson, Tony (2013c) 'What is this 'School' called Neoclassical Economics?' Cambridge Journal of Economics, 37(5):947-983.

Lawson, Tony (2014) 'Comparing Conceptions of Social Ontology: Emergent Social Entities and/or Institutional Facts?' mimeo: Cambridge.

Lowie, R. H. 1937. The History of Ethnological Theory, New York, Holt, Rinehart and Winston.

Mayhew, Anne (1998) "On the difficulty of evolutionary analysis”, Cambridge Journal of Economics, 22, 449-461

Miller, Edythe S. (1992) “The Economics of Progress.” Journal of Economic Issues 26 (March): 115-124.

Mitchell, Wesley Claire (1929) 'Thorstein Veblen: 1857-1929.' [Obituary] 'Economic Journal', Dec., 1929, vol. 39, pp. 646-650.

Munkirs, John R. (1998) “The Dichotomy: Views of a Fifth Generation Institutionalist.” Journal of Economic Issues 22, no. 4 December: 1035-44.

Peukert, Helge (2001) "On the Origins of Modern Evolutionary Economics: The Veblen Legend after 100 years." Journal of Economic Issues 34(3): 543-556, September.

Ranson, Baldwin, (2010) John Fagg Foster's Contribution to Scientific Enquiry. Downloadable from: http://jfaggfoster.org/FosterByRanson.pdf 
Ramstad, Yngve (1995) “John Commons's Puzzling Inconsequentiality as an Economic Theorist." Journal of Economic Issues 29, no. 4 (December): 991-1012.

Riesman, D. (1963). Thorstein Veblen: A Critical Interpretation, New York, Charles Scribners.

Samuels, Warren. J. (1990) “The Self-referentiability of Thorstein Veblen's Theory of the Preconceptions of Economics Science", Journal of Economic Issues 24 (3): 695-718, September.

Samuels, Warren. J. (1998) "Comment on 'Postmodernism and Institutionalism'”, Journal of Economic Issues 32 (3): 823-32, September.

Searle, John. R. 2010. Making the Social World: the Structure of Human Civilisation, Oxford: Oxford University Press.

Sowell, Thomas (1967) 'The 'Evolutionary' Economics of Thorstein Veblen', Oxford Economic Papers, New Series, Vol. 19, No. 2. July, pp. 177-198.

Spencer, Herbert (1855) Principles of Psychology, London: Longman, Brown, Green and Longmans

Spencer, Herbert (1857) 'Progress: Its Law and Cause', (Chapman's) Westminster Review, 11: $p p$ 445-85.

Spencer, Herbert (1862) First Principles of a New System of Philosophy, Williams and Norgate.

Stocking, G. W., Jr. 1968. Race, Culture, and Evolution, New York: The Free Press,

Tool, Marc R. (1979) The Discretionary Economy. Santa Monica, Calif.: Goodyear Publishing.

Veblen, Thorstein (1898) 'Why is Economics not an Evolutionary Science?' The Quarterly Journal of Economics, Vol. 12, No. 4, Jul, pp. 373-397.

Veblen, Thorstein (1899a [1998]) The Theory of the Leisure Class: An Economic Study of Institutions, New York: MacMillan Company. Republished as The Theory of the Leisure Class, in 1998, by Prometheus Books, New York: Amherst. Page references are to the latter.

Veblen, Thorstein (1899b) 'The Preconceptions of Economic Science I' The Quarterly Journal of Economics, Vol. 13, No. 2, Jan, pp. 121-150

Veblen, Thorstein (1899c) 'The Preconceptions of Economic Science II' The Quarterly Journal of Economics, Vol. 13, No. 4, Jul, pp. 396-426

Veblen, Thorstein (1900) 'The Preconceptions of Economic Science III' The Quarterly Journal of Economics, Vol. 14, No. 2, Feb, pp. 240-269.

Veblen, Thorstein (1906) 'The place of science in modern civilization', The American Journal of Sociology, Vol. XI, No. 5, pp. 585-609. Reprinted in Thorstein Veblen (1919) The Place of Science in Modern Civilization and Other Essays, New York: Viking Press, pp. 1-31 (page references to the latter).

Veblen, Thorstein (1908) 'The Evolution of the Scientific Point of View', University of California Chronicle, Vol X, No. 4. Reprinted in Thorstein Veblen (1919) The Place of Science in Modern Civilization and Other Essays, New York: Viking Press, pp. 32-55 (page references to the latter).

Veblen, Thorstein (1914) The Instinct of Workmanship and the State of the Industrial Arts. Reprinted in 2006 by Cosimo: New York. Page references to the latter.

Veblen, Thorstein (1909) 'The Limitations of Marginal Utility', Journal of Political Economy, Vol. 17, No. 9, Nov, pp. 620-36.

Veblen, Thorstein (1910) 'Christian Morals and the Competitive System', International Journal of Ethics, Vol. 20, No. 2 (January), pp. 168-185. Reprinted in Veblen (1934), page references to the former/original. 
Veblen, Thorstein (1918) 'The Passing of National Frontiers', The Dial, LXIV, February 25. Reprinted in Veblen (1934), page references to the latter.

Veblen, Thorstein (1919) 'Bolshevism is a Menace - To Whom?', The Dial, LXVI, February 22. Reprinted in Veblen (1934), page references to the latter.

Veblen, Thorstein (1925) 'Economic Theory in the Calculable Future', American Economic Review, Vol. XV. No 1 Supplement, March. Reprinted in Veblen (1934), page references to the former/original.

Veblen, Thorstein (1934) Essays in Our Changing Order, edited by Leon Ardzrooni, New York: The Viking Press.

Waller, William (1982) "The Evolution of the Veblenian Dichotomy: Veblen, Hamilton, Ayres, and Foster.” Journal of Economic Issues, 16, no. 3 (September): 757-71.

Waller, William (1987) "Ceremonial Encapsulation and the Corporate Cultural Hegemony." Journal of Economic Issues 21 (March): 321-28.

Waller, William (1988) 'The Concept of Habit in Economic Analysis', Journal of Economic Issues, Vol. 22, No. 1, March, pp. 113-126

Wisman, Jon D., and James F. Smith (1999) “American Institutionalism on Technological Change.” Journal of Economic Issues 33, no. 4 (December): 887-902. 